University of Rhode Island

DigitalCommons@URI

Open Access Dissertations

1975

\title{
Assessment of Visual Memory in Elementary School Children Under Motivating Conditions
}

Charles Walter Paskewicz

University of Rhode Island

Follow this and additional works at: https://digitalcommons.uri.edu/oa_diss

\section{Recommended Citation}

Paskewicz, Charles Walter, "Assessment of Visual Memory in Elementary School Children Under Motivating Conditions" (1975). Open Access Dissertations. Paper 1070.

https://digitalcommons.uri.edu/oa_diss/1070

This Dissertation is brought to you for free and open access by DigitalCommons@URI. It has been accepted for inclusion in Open Access Dissertations by an authorized administrator of DigitalCommons@URI. For more information, please contact digitalcommons-group@uri.edu. 
ASSESSMENT OF VISUAL MEMCRY IN E'EEMENTARY SCHOOL CHILDREN UNDER MOTIVATING CONDITIONS

BY

CHARLES WALTER PASKEWICZ

A DISSERTATION SUBMITTED IN PARTIAL FULFIIIMENT OF THE REQUIREMENTS FOR THE DEGREE OF

DOCTOR OF PHILUSOFHY

IN

PSYCEOLOGY 


\title{
ASSESSMENT OF VISUAL MEMORY IN ELEMENTARY SCHOOL
}

CHILDREN UNDER MOTIVATING CONDITIONS

\author{
Abstract
}

Visual memory as traditionally defined is a confounded measure, intercorreloted with visual processing abilities of discrimination and copying. In this study visual memory performance was conceptualized to exclude the effects of copying disabilities. The derived measure of visual memory was the difference between a reproductionfrom-memory score and the score obtained on an equivolent copying task. Copying was considered a complex function including discrimination and visual-motor integration. These definitions were necessary to separate out the factors in visual memory assessment and thus provide for a differential diagnosis of visual processing disabilities.

Visual discrimination, copying and reproduction-frommemory measures were hypothesized to be intercorrelated, reflecting the confounding of the measures, and since discrimination, visual-motor integration and visual memory were defined as separate abilities, they were not expected to be correlated. In oddition bypotheses were made concerning the effects of sex, age and intelligence level of the child and sex of the examiner upon discrimination, integration and memory. A test battery was administered to 320 white elementary school children divided 
equally into groups for levels of sex, high and average IQ, and eight age groups, 6 - 10. Half the children were administered the test battery by male examiners, half by female examiners. Previous research demonstrated significant effects of mötivation on visual processing measures. Therefore, all tests were administered under motivating conditions, the promise and immediate payment of one penny for each correct response.

The tests consisted of a visual discrimination test prepared by the author, the copying administration of the Revised Visual Retention Test (Benton, 1963) and the reproduction administration of that test. Using a paired comparison administration format, the discrimination test wos designed to approximate the errors possible in the other two test conditions.

Results indicated that measures of discrimination, copying and reproduction were intercorrelated suggesting that they are confounded measures of separate abilities. The discrimination measure and the derived measures of visual-motor integration and visual memory were not intercorrelated indicating that separate abilities are being measured. Norms were established for these measures under motivating conditions to facilitate differential diagnosis.

The hypothesis that sex of the child would make no difference on any of the measures wos accepted. The sex of the examiner, however, influenced the measure of visual memory in that children made more errors with female examiners. 
Age of the child effected the measures of discrimination and memory but not the derived visual-motor integration measure. Intelligence of the child effected only the discrimination measure in that above average children made fewer errors than average children.

The finding of no significant main or interaction effect for the derived visual-motor integration led to the conclusion that integration may be a constant factor in elementory school children.

Norms reflecting these significant findings of assessment condition effects were presented for all the measures under motivating conditions. These norms on both the traditional and derived measures, since they help to specify the nature of visual processing, should facilitate more focused and effective remediation attempts. 


\section{ACKNOWIEDGMENTS}

I am deeply indebted to Steve O'Keefe, my major professor, for much more than the time and effort he spent helping me through this dissertation. He has taken the time to model for me what he knows and how he operates, teaching me about school psychology. If graduates still talk with pride in having been someone's student, I indeed am proud to have been a student of Dr. O'Keefe.

Many thanks to the other members of my committee; to Dr. Janet M. Kulberg, who sparked my drive toward completion by handing me notices of job openings;

to Dr. Stanley I. Berger, who supported my work from the beginning and spent much time trying to make a clinician out of me;

to Dr. John V. Iong, who agreed to join my committee when I needed him at the last minute when all the work was there to do and none of the satisfactions of helping create it.

There were many people without whose help this work would not have been completed without long delays. II would especially like to thank Barbara Schooler and Douglas Schooler. Barbara found a new profession as a research assistant, and Doug remains no stranger to late-into-thenight discussions about this research.

Special thanks to Dr. William T. Yosburgh, Director of the URI School Psychology Progrom, who guided me through dimensions of school psychoiogy very few have the opportunity to experience and learn from. 
This work is dedicated to two women who have helped shope my Iife:

To Mary Berk, Ph.D., whose clinical skills and friendship kept me together and in graduate school long enough to learn from her and the experience of graduate school.. I sholl ever owe her a debt of gratitude.

To Kristen Kask, "It is only with the heort thot one con see rightly." 
TABIE OF CONTENTS

Page

Acknowledgments . . . . . . . . . . . . . ii list of Tables . . . . . . . . . . . . . vi vi List of Figures . . . . . . . . . . . . . vil Chapter

I. Statement of the Problem . . . . . . . . I Introduction . . . . . . . . . . . . . I Need for the Study . . . . . . . . . 3 Purpose of the Study ........... 5 Definitions of Terms . . . . . . . . . 6

II. Review of the Iiterature . . . . . . . . IO Factors in Memory ........... . . . . Factors in Perceptual Assessment . . . . 14 Tests of Visual Memory . . . . . . 20 Environmental Variables . . . . . . . 23 Summery . . . . . . . . . . . . . 33

III. Hypotheses and Methodology .........35 Introduction . . . . . . . . 35 Hypotheses . . . . . . . . . 35 Methodology ............... 36 IV. Results of Statistical Analyses . . . . . 42 Eypotbeses . . . . . . . . . 42 other Findings . . . . . . . . . 61 7. Conclusions . . . . . . . . . . 71 Measures of Visual Processing . . . . . . .71 Variabies Affecting Assessment of Visual

Processing ............... 76

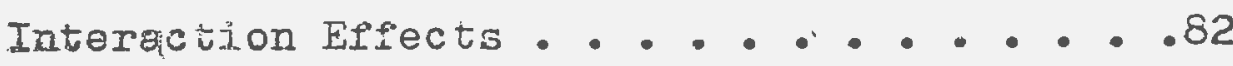


Chapter

Poge

VI. Implications of this Research . . . . . 86 Implications for Diagnosis . . . . . 86 Implications for Future Research . . . . 88

Appendix A: Discrimination Means and Standard

Deviations ............ . . 95

Appendix B: Visual-Motor Integration Means and

Standard Deviations . . . . . . . 97

Appendix C: Visual Memory Means and Stondard

Deviations . . . . . . . . . 99

Appendix D: Visual-Motor Integration Means and

Standard Deviations Using Negative

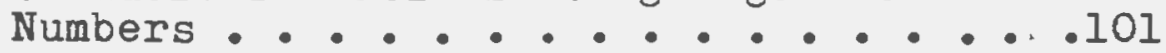

Appendix E: Analysis of Variance for Visual-Motor

Integration Using Negative Numbers for

Sex, Age, and IQ of the Child and Sex

of the Examiner .............. . . . . .

Appendix F: Norms for the Discrimination Measure . 105

Appendix G: Norms for the Visual-Motor Integration

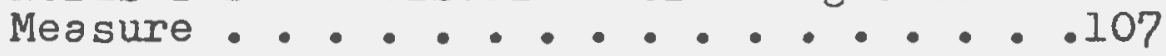

Appendix H: Norms for the Visual Memory Measure.. • 109

Appendix I: Norms for the Copying Measure . . . . . Ill

Appendix J: Norms for the Reproduction Measure . . 113

Appendix K: Raw Data................115

References . . . . . . . . . . . . . . . . 24 


\section{IIST OF TABLES}

Table

Page

1. Intercorrelations among Traditional and Derived Meosures......... . . . 44

2. Multivariate Analysis of Variance of Error

Scores for the Three Dependent Measures

for Sex, Age, and IQ of the Child and Sex

of the Examiner ... . . . . . . . 46

3. Visual Processing Error Scores for Sex of Ghild ... . . . . . . . . . 47

4. Analysis of Variance of Discrimination Error Scores for Sex, Age and IQ of the Child and Sex of Examiner . . . . . . . . 4 48

5. Analysis of Variance of Visual Memory Error Scores for Sex, Age, and $I Q$ of the Child and Sex of Examiner....... . . 49

6. Analysis of Variance of Visual-Motor Integration Error Scores for Sex, Age, and IQ of the Child and Sex of Examiner ....... 51

7. Error Scores for Traditional and Derived Measures over Age . . . . . . . 56

8. Analysis of Variance of Copying Error Scores for Sex, Age and $I Q$ of the Child and Sex of the Examiner........... . . 57

9. Analysis of Variance for Reproduction-fromMemory Error Scores for Sex, Age, and IQ of the Child and Sex of the Examiner . . . .58

10. Error Scores of Reproduction-from-Memory, Copying and Visual Memory for Sex of

Examiner ................ 62 


\section{IIST OF FIGURES}

Figure

Page

1. Pattern of Scores for the Discrimination

Task over Age.......... . . 52

2. Pattern of Scores for the Visual Memory

Task over Age........... . 53

3. Pattern of Scores for the Discrimination,

Copying and Visual-Motor Integration Tasks

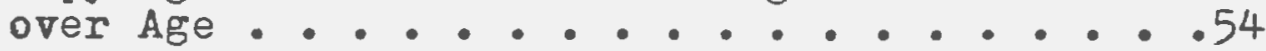

4. Pattern of Scores for Reproduction-from-

Memory, Copying and Visual Memory over Age . .60

5. Pattern of Error Meons for Reproduction-from-

Memory, Copying, and Visual Memory for both

Sexes of Examiner .......... 63

6. Pattern of Scores for Visual Memory Showing the Sex of Examiner by IQ Category

Interaction ........... . 65

7. Pattern of Scores on the Visual Memory Task Showing the Sex of Examiner, Sex of Child, and IQ Category Interaction . . . . . 67

8. Pattern of Scores for Boys on the Visual-Motor

Integration Task by Sex of Examiner . . . 69

9. Pattern of Scores for Girls on the Visual-

Motor Integration Task by Sex of Examiner . . 70 


\section{Chopter I}

Statement of the Problem

Introduction

1 particular focus of concern recently in school psychology has been the area of visual memory functioning. Carroll (1974) notes the increasing interest in this function and reasons that it is because of the relationship between visual memory and reading problems. Learning disabilities, and some aspects of central nervous system impairment may also be related to visual memory functioning. Visual memory may be an important factor in many areas of the learning process since for academic subjects, especially reading, the child must be able to recall information which has been presented visually. It is clear that on accurate description of the child's strengths and weaknesses, especially in this area, may be helpful in understanding how a child functions in relation to his learning environment.

One of the problems in visual memory assessment revolves around the functional complexity of the test instruments. Conventional tests of visual memory require a. subject to study a series of stimulus cards one at a time, each one containing one or more designs. After hoving seen it for a brief time, the person is required to drow what he has seen when it is removed, using pencil and paper for the reproduction. Such tests are functionolly complex in that they measure not one, but some combination of factors. They measure perceptual, integration, 
ond motor functions as well as memory. When a subject performs poorly, the question is unanswered whether this performance reflects a visual perception disturbance, a visual-motor dysfunction, or a visual memory deficit. If a person suffers from a disturbance of visual perception or a visual-motor integration handicap, his visual memory score may be invalid (Silverstein, 1962). Typical administration of a reproduction-from-memory test does not offer diagnostic information separating out the differential effects of perception, integration and memory (Aliotti, 1974).

Moreover, the difficulties that are present in the orea of visual memory assessment are also contained in the assessment of the subcomponents. Most tests mersuring perceptual skills are confounded by a complicated grophic encoding requirement. And converself, tests of copying are complicated with the perceptual factor.

In addition, the concept of motivated testing has never been fully examined with regard to memory evaluations of this type. At the 1974 convention of the American Psychological Association, a visual memory assessment symposium openiy recognized the lack of inherent motivation in visual memory tests (Fuller, 1974). In many instances the task is not sufficient to sustain the child's interest in the test, thus creating a situation in which both reliability ond test validity are lowered. The application of a motivating condition in the form of reinforcement may be an especially important factor in 
any attempt to assess visual memory ability.

The lack of differentiation of factors in tests of visual memory ability, as well as assessments conducted under "non-motivated" conditions, may confound a diagnosis of visual memory dysfunction and spuriously inflate the incidence of visual memory dysfunction among those elementary school children referred for learning disability evoluations.

\section{Need for the Study}

In the past ten years much attention has been spent on visual functioning by educators and school psychologists. Colarusso (1971) suggests that this interest reflects a view of perception's critical importance to longuage facility and academic achievement, especially reading. Many training programs have been implemented in and out of schools for learning disabled children with perceptual handicaps for the purpose of remediation and/or compensation of the deficits involved in visual functioning.

However, studies report no resl effect of these training programs on school achievement. Studies which report gains are too easily criticized methodologically (Fach, 1971). She attributes the lack of clear cut results from such training prograns to a lack of clear understanding of the measurements used in identifying these children. Although perception is essential for learning, and training in perceptual skills may help in preparing 8 child for successful school achierement, questions remain 
concerning the validity of current assessment procedures. While there is general agreement in defining perception as on information processing system whereby input from the senses is translated into knowledge, operational definitions, determined by the instruments used, may be quite discrepont. Two investigators, both talking about perception, may in fact be measuring two different aspects. Need exists then for an investigation of the factors that are responsible for successful performance on tests used to diagnose perceptual deficits, such as visual memory. There is a need to develop a measure which assesses visual memory unconfounded by other measurement variables. There is also need for the establishment of more precise norms which control for the relevant contextual variables of the assessment procedure.

Recent attempts to develop motor-free tests of visual memory have concentrated on multiple-choice formats for use with children who are developmentally unable to reproduce the rather complex designs found on existing reproduction tests of short-term memory. These ottempts ore valuable in the assessment of kindergarten children, and children who are motorically handicapped. However, such tests may not be evaluating the relationship with visurl memory as tested in the schools, since the common response expected in schools is a grophic one. Such tests also introduce difficulties of perceptual analysis and synthesis which in the past hove complicated perceptual testing (Rosenblith, 1965; Zach, 1971): 
There exists a need for a comparative analysis of the development of discrimination, visual-motor integration and memory abilities to aid in the differentiol aiagnosis of visual functioning disorders in elementary school children. Such specific differential diagnosis, leading to understanding the individual child's strengths ond wéaknesses, logically precedes the planning and controls the effectiveness of remediation programs. Remediation will be successful only when the problem is accurately defined. This study is an attempt to define the status of the developmental factors underlying successful performance on a test of visual memory.

\section{Purpose of the Study}

The primory purpose of this study is to investigate visual memory abilities in elementary school children. Recognizing the functional complexities of the measuring instrument, an attempt has been made to separate out the factors involved in visual memory performance. These factors include discrimination and visual-motor integration.

In oddition to the confounding variables with the test itself, on investigation. was made concerning the effect of environmental variables which in the past have been seen as factors affecting performance. Thus, there was consideration of the relationship between the sex of the experimenter, the sex, age, and intelligence category of the child and the measures of visual functioning: discrimination, visual-motor integration and visual memory. 
Moreover, an attempt was made to control for the "paying attention" factor. The significant effect of reinforcement on the subcomponents of visual memory evaluations has been demonstrated (Paskewicz \& Weaver, 1975). Reinforcement functions as an incentive to focus and sustain attention. Recognizing the power of this variable all testing procedures were carried out under reinforcing conditions. Operationally defined, reinforcement consisted of the promise and immediate payment of one penny for each correct response on the three tasks. In the discrimination task, one penny was given to the child for each correct same-different judgment. In the copying and reproduction-from-memory tasks one penny was given for each page approximating the standard.

\section{Definition of Terms}

The confusion in the area of the assessment of visual processing dysfunctions revolving around the functional complexity of the measuring instruments is further oggrovated by imprecise language used to describe the concepts involved in a model of visurl functioning. Attention must be directed at more clearly defining the terms. Visual Discrimination. This is a complex set of reactions within the central nervous system which permits recognition of an external stimulus. It involves decoding and associative processes. This reception and recognition is based on the ability to compare stimulus pairs and moke judgments concerning their similarity ond difference. In this study, visual discrimination was operationally 
defined as the score obtained by counting the number of exrors produced when comparisons were made on a discrimination task. This task compared the design cards of Form $C$ of the Revised Visual Retention Test (Benton, 1963) and design cards prepared by the author. Some of these cards were similar, and some were different varying along a number of error dimensions including omission, distortion, rotation, misplacement and size errors.

Motor. This is concerned with the execution of muscular activity, originating within the central nervous system. Motor activity is an encoding process at the nonsymbolic level. In this study no measure of motor activity was taken, but care was given to the elimination of those children who evidenced graphic motor encoding difficulties. Copying. This involves the skill to relate visual stimuli to motor responses. A copying act involves the integration of decoding, association and encoding processes. The Bender Visual-Motor Gestolt Test (Bender) would be $8 \mathrm{n}$ example of a copjing task. In this study, copying was operationally defined as the error score obtained on Administration " $C$ " (direct copying) of Form $D$ of the Revised Visual Retention Test (RVRT). Visual-Motor Integration. This refers to the integration of decoding, association and encoding processes given that the effect of decoding errors are eliminated and that special encoding difficulties are taken into account. The Bender would reflect visual-motor integration if the number of discrimination errors and graphic-motor response 
errors were taken into account. In this study, visualmotor integration was operationally defined as that score obtained by calculating the difference between the score obtained on the copying task and the score obtsined on the discrimination task.

Reproduction-From-Memory. This refers to the ability to reproduce the stimulus in the absense of the stimulus. The person is shown a stimulus card for a certain period of time which is then removed, the person now being required to draw what he has seen. This ability combines the skills of decoding, association, encoding as well as memory. In this study, reproduction-from-memory was operationally defined as the error score obtained on Administration "A" (reproduction following ten second exposure) of Form $\mathrm{E}$ of the RVRT.

Visual Memory. This refers to the process in which visual stimuli are stored for future visualization. A memory performance reflects visual memory ability when decoding, integration and encoding deficits have been taken into account. In this study visual memory was operationally defined as that score obtained by calculating the difference between the score obtained on the reproductionfrom-memory task and the score obtained on the copying task.

In the past lack of differentiation of these terms has led to misunderstanding of the nature of visual processing difficulties. For example, the Bender was defined os 8 visual-motor integration test. Poor performance was 
then equated with a deficit in visual-motor integration ability. However, the test is functionally complex in that it measures more than one ability. A below age expectation performance might reflect either a difficulty with discrimination, integration or graphic encoding ability. Visual-motor integration connot be defined as the source of the difficulty until discrimination and encoding have been eliminated as the source.

The norms for the RVRT list the errors as reflecting either visual-motor or visual memory disabilities. Poor performance on Administration "A" could reflect either memory, discrimination, integration or encoding difficulties. It reflects memory when copying errors (containing within it the discrimination, integration and encoding errors) are taken into account. For example, if a child mokes twelve errors on the reproduction-from-memory task and makes ten errors on the copying task, then he obtains a score of two on visual memory, since ten of the reproduction-from-memory errors are explained by errors in the perceptual process. So while it is possible to obtain a high error score on reproduction-from-memory, a score supposedly indicating the presence of a specific memory disability, this may not reflect the actual presence of such a problem, but only the presence of confounding. perceptual variables. 


\section{Chopter II \\ Review of the Iiterature}

This chapter will review the analysis of factors involved in visual memory and the assessment of visual memory ability particularly those factors which complicate evaluations, namely, discrimination and visual-motor integration abilities. In addition, variables which may affect the testing situation and underlie individual ond/or group differences, i.e., sex of the examiner, sex, oge, and intelligence level of the child will be examined. Moreover, the effect of motivation in perceptual functioning testing will be discussed.

\section{Frators in Memory}

Memory is the retention of what has been learned or experienced (Eliot, 1971). Reese ond Iipsitt (1970); comment thot while experimentol research in the orea of memory hos been increasing, there exists a surprising lack of interest on the part of many child psychologists, despite evidence that short-term memory developes with age (Maccoby \& Hagan, 1965): They suggest that a systematic examination of the characteristics of memory in children along developmental lines would add to the understonding of memory processes. This is especiolly true since in the broodest sense memory is involved in all psychological activity.

The variables which account for individual variation in the quality of memory include 1) the availability of cognitive units, 2) attention and 3): motivation (Kagan \& 
Kogan, 1970). First, memory is a complex measure being made up of the amount of acquisition of information during the presentation period, the rate of forgetting, and the accuracy of retrieval of non-forgotten material. The rate of forgetting does not develop across age. Acquisition and accuracy of non-forgotten material are then possible developmental variables. The evidence bearing on the development of immediate memory is dramatically different from that concerning the development of retention. The developmental studies agree that short-term memory increases over a wide age range, and increases with intelligence. The conclusions regarding memory, as opposed to retention, indicate that older and more intelligent people employ more active acquisition strategies. In other words, one of the major reasons for poor recall is the lack of an efficient mediational process (Belmont \& Butterfield, 1969).

Reese (1962): labeled the lack of verbol mediation of overt behavior in children the "mediational-deficiency" hypothesis. Mediation is absent even in the presence of demonstrated ability to understand and correctly use the appropriate words in question. The child does not use the words he knows as a memory aid, i.e., labeling the objects-to-be-remembered. The discrepancy between linguistic and mediational capacities becomes reduced with age, and the deficiency disappears. Flavell, Beach \& Chirsky (1966) have postulated the existence of a "production deficiency" as possibly co-existing with the other 
hypothesis. This new hypothesis implies that the child's difficulty may not lie in an inability to use words which he produces in a mediational fashion, but rather in the lack of ability or disposition to produce them on appropriate occasions. The results of their study confirm the existence of "something akin to verbal production deficiency in young children." They suggest two basic reasons why chilaren might fail to use the naming and rehearsal to aid in recall. First, while children may have language ability, the rules that regulate its use across social situations and contexts may be independent and limited. Second, failure of the children to "talk to themselves" may have nothing to do with their level of linguistic competence, but reflect a general cognitive immaturity revolving possibly around notions of intellectual activity, and the development of the capacities of sustained attention, problem-solving and time-binding. Findings that children from language-poor environments exhibit performance deficits on memory tasks, and do not seem to assimilate new information with the accuracy. and extensiveness of children with richer language resources reinforce these ideas (Cazden, 1966; Hess \& Bear, 1968).

A second variable in the quality of recall is the lock of selective attention which leads to imperfect registration of events, even in short-term memory. Two foctors could result in lack of attention: interfering responses and distracting stimuli. The most consistently replicated finding is the negative relationship between 
anxiety and immediate recoll, in that anxiety creates distrocting stimulation which deflects attention from relevant incoming information and thus impairs memory. The negotive correlation between test anxiety and verbol skills is congruent with the idea.

Iastly, individual differences in memory also vary with motivation. The child's attention to the task will be enhanced if he is motivated to attend to the events. If the child recognizes that attention to and subsequent mastery of a task are prerequisites for attaining a desired goal, he is more likely to make an effort at mastery. However, effort at mastery may or may not affect actual performance. Paskewicz and Weaver (1975)i found differential effects of motivation on tasks of visual functioning, and found that, unlike discrimination and copying tasks, reproduction-from-memory was not affected by the opplication of a motivating condition. Although the children made more errors under motivating conditions, this difference was not significant. They concluded that when confronted with ego-involving tasks, such as memory, the children were attending to the task as best they could, and that the addition of a reinforcing event could not increase attention. Since the reproduction-from-memory errors did not significontly increase, the possibility of interference by anxiety was not considered. Using the definitions outlined in the first chapter, they went on to point out that since visual memory is operationally defined as the difference between reproduction-from-memory 
ond copying scores, visual memory errors actually increase under conditions of motivation. Under motivation copying errors are dramatically reduced, and reproduction errors remain stable, visual memory errors appear to increase. Analysis of the factors that comprise the concept of how much a person remembers is necessary in accounting for the poor memory performance of any individual person. There is presently available a body of research concerned with organizational factors in children's recall, as well as investigations of individual differences in recall along with the dimensions of mediation availability and use, attention and motivation. It appears that what is necessery now is the establishment of norms of short-term memory for clinical use taking into account age and intelligence level. Children who perform below age and intelligence expectancy on such a measure may then be the focus of attempts at differential diagnosis to uncover the component deficit underlying the disability. It may well be that concentration on acquisition strategies relating to the use of verbal mediators is the most valuable remediation technique. What is still primarily lacking is a clinical measure of short-term memory. Factors in Perceptual Assessment

In the introductory chapter, we noted the difficulties in assessment of visual memory using a paper and pencil method. The functional complexity of such an evaluation confounds the memory variable with discrimination, integration and encoding skills. Most conventional tests of 
visual memory involve considerable motor functioning in the form of drawing (Bannatyne, 1969): However, there is much confusion even in the area of "perceptual" assessment. This confusion revolves around the differential diagnosis of perceptual and integrative abilities. Newcommer and Hammill (1973) report that motorically handicapped children perform progressively poorer on a test of visual-motor integration (their use of the term) as the severity of their motor handicap increases. Conversely, they tend to function appropriately for their chronological age on a motor-free test of visual perception regardless of the level of motoric disability. They do not have difficulties with visual perception which are commonly attributed to them. Children's visual perception should be measured independently of motor development, lest we fail to differentiate between the two and regard visual-motor integration test results as measures of visual perception. Visual perception and visual-motor integration are relatively separate systems (Rosenblith, 1965).

Birch and Lefford (1967). investigated the developmental changes in the ability to copy a two-dimensional design in children five to eight years of age. They concluded that perception of visual forms was not a unitary phenomenon, but rather it involved a "multi-leveled set of functions . . composed of a number of processes characterized by different degrees of functional complexity and different ages of maturation ${ }^{n}(p .9)$. They investigated the relationship between visual differentiation, 
Intersensory integration and voluntary motor performance. Differentiation includes discrimination, perceptual analysis and perceptual synthesis. Perceptual analysis refers to the individual's capacity to segregate, identify and respond to selected aspects of the whole figure. Perceptual synthesis refers to the ability to reorder linear elements, fragments of forms or any number of arbitrary subwhole aggregates into coherent spatial distributions which will result in the whole figure.

Their main finding in relation to differentiation was that by age five normal children had high ability to discriminate among simple plain figures. Also errors made in discrimination of such figures at ages five to seven years frequently reflected failure to utilize the spatial orientation of the figure or its properties of axial symmetry as discriminanda. These errors fell off with oge ond occurred infrequently by age nine.

Their main findings in relation to copying ability was that the ability to draw geometric forms increased with age. Also individual variability decreased with age. In addition, they found that the most rapid rate of development in the ability to copy designs occurred between oges five and six.

Their findings relating copying ability and the discrimination measures are surprising. They found that neither perceptual analysis nor synthesis was related at ony given age with the ability to copy a design. Both had a weak but significant relationship with copying when all 
the subjects were pooled across age.

It is surprising to find a lack of relationship between discrimination and copying, when conceptuslly discrimination is necessary for copying. However, the explanation offered is more surprising in its confusion. "Each (analysis and synthesis) is only weakly associated with motor functioning when such motor functioning is estimated in terms of the drawing of a visually presented model on a blank page" (p. 80). Iater in the same paragraph they talk of these measures being strongly associated with intersensory functioning and state that "when the messure of motor integration used is copying a visually presented model on a blank page, intersensory integration is . - strongly associated with the other variables studied" (p. 80). Copying is used both as a measure of motor functioning and motor integration, and not as a measure of copying.

Significant differences in a matching discrimination test between groups of children separated on the basis of their performance on the Bender suggests at least a measure of correlation between discrimination and copying (Wedell and Horne, 1969). This correlation is not surprising if we take the Bender scores as measures of copying, and not of integration. A relationship is expected between discrimination and copying since discrimination is a part of copying. And yet the practical implications of the controversy and rediscovery of component analysis still continues. 
Simpson (1974) administered both the RVRT and the Bender and a multiple-choice version of the Bender, as well as the Peabody Picture Vocabulary Test (PPVT) to thirty spastic and thirty athetoid seven to ten year olds. Results show that perceptual functioning, rather thon being a single entity, can be differentiated into discrimination and perceptual-motor integration components. Again we must remember that the Bender is a copying test and that if separate scores were obtained for discrimination functioning, those errors labeled as perceptualmotor integration errors would indeed reflect integration if the discrimination errors were taken into account. Errors due to an inability to discriminate the visuel input cannot also then be a part of the perceptual-motor integration definition.

Anglysis of the errors in the Simpson study shows that the easiest task was discrimination (multiple-choice form); more difficult was the copying test (Bender); most difficult was the reproduction-from-memory test (RVRT): Difficulty is reflected in incressed numbers of errors. This would appear to fit the onalysis of the components in visual processing. Discrimination is a separate skill; copying requires use of that skill as well as integration ond motor encoding; reproduction-from-memory utilizes all those skills in addition to memory. Clearly it is a cumulative model: more errors with increasing complexity. However, Zach and Kaufman (1971) concluded from their onolysis of the Bender and Bender multiple-choice discrim- 
ination task error scores that performance on one task was not related to performance on the other. Not surprising was the first implication that a child could discriminate forms well and still obtain a score on the Bender which indicated "perceptual" difficulties. The educational implication is that because a child does well on a discrimination test, it cannot then be assumed that he will do well on the Bender copying test.

sturprising was the converse: that children could do well on the copying test, but poorly on the discrimination test. Either it is not true that discrimination ability is a developmental prerequisite to the more complex task of copying, or the discrimination test was measuring and drawing on otber facets of perception. An analysis of the demands of the multiple-choice discrimination task shows that more than simple, pure discrimination ability was required. For success a child had to first call from the four stimulus choices the one which correctly matched the standard, a procedure demanding perceptual analysis. He then had to organize the figures for himself in some way to drow upon some aspects of perceptual synthesis. They recommend a simple discrimination task requiring a matching of two stimuli, and a response of "same" or "different." This is in line with the Rosenblith (1965) recommendation in measuring perception that all judgments be made using a paired-comparison method. Such a method calls for the simultaneous pairing of the standard and the comparison stimuli. This method eliminates complex 
motor behavior, memory and choice from among simultoneously present alternatives as confounding variables in perceptual judgments.

Tests of Visual Memory

While a number of tasks involving visual memory have been devisea for research purposes, a limited number of tests are available for use in clinical and educational settings. Colarusso (1971) included only three widely used tests of visual memory in his summary of tests available in the area of visual perception. These include the Revised Visual Retention Test (Benton, 1963); the Memory for Designs Test (Graham \& Kendall, 1960); and the Visual Sequential Test of the Illinois Test of Psycholinguistic Abilities (ITPA): (Kirk, McCarthy \& Kirk, 1968).

Benton (1963), reviewing the normative standards for the Revised Visual Retention Test, shows that there are significant relationships between scores on the test and generol intelligence level and also between test performance and chronological age. He suggests that correct clinical interpretation can only be made within the framework of the age and IQ of the person tested. For this he provides normative standards. With certain exceptions in the cases of superior children (which is left unexplained), he suggests that an obtained score which is three points above on "expected" score (different for each age and IQ level) may be considered to raise a question of a specific disability in visual memory or visual motor functioning. An obtained score which is four points above the expected 
score may be considered to suggest such a disability, and a score which is five points above expectations (or more) strongly indicates a disability. All scores reflect error scores.

However, two immediate impressions come from viewing the table and its descriptions. The errors are reported to reflect either visual memory or visual-motor disabilities. The work of Paskewicz and Weaver (1975) indicates that there are differences between visual-motor functioning and visual memory functioning. It is also clear that reproduction-from-memory is a measure of neither. Benton provides norms only for Administration "A" which is what we call reproduction-from-memory. Norms for copying are not indicated. Surely this is not acceptable when memory evaluations are confounded by variables of perception, integration and encoding.

In his review of the RVRT for the Fifth Mental Measurements Yearbook, Hanawalt (1959): quotes the manual which states that the test is a "clinical and research instrument designed to assess memory, perception and visuomotor functions." He chides Benton in that memory for designs is different from memory in general, and he points to the decrease with age of the intercorrelations of memory tests. Also he notes the lack of ability of the test to separate perception from memory, and suggests that Administration "C" (the copying test) be also used to distinguish perception and memory from drawing and motor ability.

secondly, the norms seem to follow a smooth pattern: 
for every one year increase in age, one less error is expected; for every ten points difference in measured IQ, one less error is expected. This pattern is curious in its regularity and predictability, and provides no individual standard deviations for these categories, no information regarding the significance of the differences within this table, and thus no information regarding the development of visual memory through age. .

Memory for Designs. Payne (1959): in his review for Buros describes the Memory for Designs (MFD) test material as consisting of fifteen stroight line designs. The test requires a reproduction-from-memory after a five second exposure to the stimulus card. This is scored by an objective system and norms are available for comparison. Such a description places the MFD test in the same class, and subject to the same ills, as the RVRT. There is no way to screen out other confounding variables, studying visual memory for designs as an uncontaminated factor. Visual Sequential Memory. The Visual Sequential Memory subtest of the ITPA is also a currently available test measuring visual memory. Unlike the others, it does not require graphic motor encoding, but the placement of plastic chips in sequential order. Also unlike the others, the reliability is questionable. Test-retest rellability is between .12 and .71 as compared to .85 for the RVRT and between .72 and .90 for the MFD.

This review clearly shows that all the currently avoilable tests of visual memory lack the capacity to 
provide differential diagnostic information separating out the effects of perception, integration and encoding. This is necessary if the information gained from such an evaluation is to be clinically useful.

\section{Environmental Variables}

There are environmental, controllable variables which may affect performance on a visual memory test. Since visual memory is a derived score, variables which might offect discrimination and copying and reproduction-frommemory will be identified. Such variables may include socio-economic status, intelligence, age and/or grade level, sex of the child, sex of the examiner, motivation as well as their interactions.

Socio-economic Status (SES). Rosenblith (1965) investigated perceptual performance as separate from perceptual motor performance by means of a discrimination task consisting of comparison between a standard stimulus and alternative stimuli varying along some error dimensions. Her sample came from two schools. School A was located in a neighborhood relatively low in terms of socio-economic status. School B was operated by the State College of Education (now Rhode Island College) drawing students from oll parts of the city and comparable in many ways to private schools. It can be characterized as serving an upper middle class or upwardly mobile population.

Rosenblith was concerned with the representativeness of her sample. Her approach to this concern was a comporison of IQ distributions between the two schools. She 
found that the difference between the average IQ's of the children in the two schools was significant.

Mean IQ scores do not appear to be, however, on adequate measure of SES, but rather a measure of IQ differences between the two schools. Be that as it may, when she compared these groups for errors in her discrimination task, she found that the differences in the average number of errors between the schools (over all grades) were significant beyond the .001 level.

Issac (1971) investigated perceptual-motor functioning using the Bender and examined proficiency in that task across three groups: $\theta$ ) $\theta$ white advantaged group; b) a white disadvantaged group; and c) a black disadvantaged group. She hypothesized that joungsters from disadvantaged backgrounds would perform more poorly on the task than their age mates (first grade) from advantaged backgrounds. Her findings show that despite significant differences in verbal IQ. (as measured by the PPVT), no significant difference was found between perceptualmotor development of the white odvantaged and white disadvantaged groups. However, both of these groups were clearly superior to the black disadvantaged group. These results suggest that differences in the level of perceptual-motor functioning are more closely related to ethnicity than social class.

Comparison of these results show that: when SES is measured by average IQ differences in the two schools drowing from different populations, there is a discrimina- 
tion test performance effect; when SES is measured on the basis of the distinction of advantaged vs. disadvantaged backgrounds, this does not distinguish groups on perceptual-motor development. This discrepancy may be accounted for: the SES groups across the two studies were not comparable; the task measured was different; the definition of SES in one instance seems inadequate. Issac in her comprehensive review of the relationship of social class and perceptual development, concludes that although the research strongly suggests a significant relationship and although there has been much theorizing about what mediates this difference, there is little evidence of a specific factor underlying the deficit. Her own research results disconfirm her expectations of no SES. effect.

After reviewing these studies it seems likely that there will be no SES effect for processing abilities. Therefore, SES will not be investigated as a variable. Intelligence Level. Rosenblith (1965) investigated IQ differences as they affect error rates in her discriminotion task. She reports that for both sets of stimuli (triangles and circles) the differences in the average number of errors between the schools (over all grades): are significant beyond the .001 level. Remember the differences which she labeled SES were in actuality IQ related. The F ratios for the two schools combined are not significant over all grades, although one or two grades differ significantly on one stimulus or the other. The mean 
number of errors shows a steady decline with grade. There is a highly significant relationship between grade level (one through four) and the school (reflecting so-called SES measured by IQ) for the two stimuli. So there was a grade by $I Q$ interaction. IQ was related to errors at each grade level: the higher the IQ, the fewer the errors. She reports, however, that $I Q$ accounts for only a smaII percentage of the variance in these perceptual tasks (thirteen percent for triangles and seven percent for circles); This was true when the children from both schools were combined.

She continues her onalysis when she states that IQ and errors are related for the lowest IQ groups, i.e., IQ's less than 86. Although she does not report statistical data, the graphs of the errors by IQ scores seem to divide errors by three IQ groups: 1) less than 86; 2) 86 - 115; and 3) 115 and above. So if we are dealing with a learning disabilities population, for whom the requirement is normal or above average intelligence, the two groups we would be interested in looking ot ore the second and the third.

Issac, on the other hand, found no significant difference in errors for differing SES level whites, despite significant differences in verbal IQ. Verbal IQ was measured by the PPVT. She found no IQ by errors interaction. Nickel (1969): found that visual discrimination is not on independent developmental process, but is significantly linked with the child's intellectual capacities. 
Grines (1969), however, found no relationship between IQ and her discrimination task with children ages four to seven. Nickel studied children aged four to five and onehalf.

Benton, although he does not report statistical data, does provide separate norms for each IQ level from defective, borderline, low average, average, high average, superior to very superior. In each case the average error score is different. These error scores may or may not be different from each other in either $a$ real or statistical sense. It seems more realistic to imagine two levels of IQ making a difference in error scores, although this difference might not be significant, looking at the Rosenblith groph.

With respect to visual-motor integration, Issac found no relationship between IQ and copjing ability. She also found no relationship between discrimination and copying. Given our definition of visual-motor integration os the difference between these meosures, error scores for visual-motor integration are not expected to vary with IQ.

After reviewing these studieg it seems likely that if IQ will make a difference on the measures of visual processing, that difference will be between two groups of children, those selected with average intelligence, and those with above averoge intelligence. Children with below average intelligence will not be studied since the measures being investigated relate to learning disabilities 
classification and placement. Learning disabilities diagnosis requires the presence of at least average intellectual functioning.

Age and/or Grade Level. Rosenblith (1965). reports that performance does improve with age or grade in school along the two dimensions of the number of errors and the number of children making errors. This was true across schools. When she examined the relationship between chronological age and performance, she found that CA is significantly related to performance across the entire range. The older the children, the fewer the errors. Relations within a single grade a re complicated by factors of early admission and repeaters. So age norms are more representative than grade norms and are therefore preferred.

Aliotti (1974); found grade level significance in a test of visual-spatial memory between children in first and second grades. Keely (1971). also found that performance improved with age on a visual memory task in pre-school children. Gaines (1969): found older children superior in her task of discrimination. Colarusso (1972), when he compared across age on his Motor Free Test of Visual Perception found significant differences. Benton also reports error scores by age, each age with a different expected score, fewer errors with increasing age. Issac (1971) on the other hand reported that the relationship between age and error scores on her task reached significance only for girls. There might then be a sex by age interaction which would affect the establishment 
of norms.

After reviewing these studies, it seems that visual processes develop over age. Norms collected must then reflect the age of the child. Grade level will not be used because of the admonition of Rosenblith concerning early admissions and repeaters.

Sex. Rosenblitb (1965) found no significant differences in either the number of errors made or the number of children making errors between boys and girls overall. Boys were worse then girls in the average number of errors for School B kindergarden tested by a female. She suggests that not much weight be placed on the overoll data since these were collected partly by mole and partly female experimenters. Despite this suggestion there exists a possibility that the sex of the experimenter may have an effect on evaluations with younger gir住. Therefore, sex of the experimenter will be taken into account. If the sex of the experimenter should prove significant, future interpretations of test results must include consideration of this non-visual-processing variable.

Issac (1971) found a significant sex by motivation interaction such that girls (regardless of SES) were better able than boys to improve their scores, $1 . e .$, make fewer errors, in response to the promise of a reward. Sex, by itself, was not related to errors. Colarusso (1972): also found no sex differences on the visual discrimination and visual memory tasks on his motor free test. Aliotti (1974) in reporting the results of his study on the validity and 
reliability of the Bannatyne Visuo-Spatial Memory Test found no significant sex differences.

Motivation. As was suggested previously in this chapter, attention, motivation and memory are related to individual variations in performance. Indeed it seems obvious that it is necessary to account for variation due to attention and motivation.

In mony instances the task of the test is not sufficientIy attractive to sustain the child's interest or motivation in the test, thus creating a situation in which both reliability and test validity are lowered. The 1974 APA convention hosted, a visual memory assessment symposium where the lack of inherent motivation in taking visual memory tests was recognized. Husted, Wallin and Wooden (1971)) experimented with the insertion of reinforcers during test administration in a Cattell Infont Intelligence scale. Their premise was to increase the sustained ottention in the test-taking experience since the test items do not have inherent motivational value. Their results show more consistent, accurate responding when 1tems are reinforced. Many other investigators, experimenting with the effect of reinforcers on test results, report significant results such that higher scores are obtained (Ali \& Costello, 1971; Butterfield \& Zigler, 1968; Rowley \& stone, 1964; Cranda11, 1963):

Issac (1971) found no main effect for motivation as It affected discrimination and perceptual-motor development in first graders. After her extensive review of the 
literature relating test performance ond level of motivation, all of which pointed to the necessity of raising motivation to allow more valid comparisons of ability levels, she defined motivation operationally as the promise of a piece of candy. The child was not given this candy until after twice performing on the Bender. The instructions told the child that although his first attempt at reproducing the cards had been good, he would be allowed to select a "treat" from the bag of candy if he would try to do even better on his second attempt at drowing the designs. It is not surprising that she found no significant main effect for motivation. Promises would not appear to act as much as a reinforcer as the actual presentation of the candy during the task.

Her results are in direct contrast to the Nickel (1969) and Ramey and Goulet (1971): studies. They both show significant positive motivation effects in visual discrimination such that immediate reinforcement raised the performance of the children. Her results are also in contrast to the results of the Paskewicz and Weaver (1975) study. They hypothesized that motivation would offect the number of errors, reducing them across the discrimination task, the copying task and the reproduction-from-memory task. Analysis revealed that motivation hod an effect only on the discrimination and copying tasks, and not on the reproduction-from-memory task. The scores for reproduction-from-memory did not differ ocross levels of motivation. 
Motivation functions as an incentive to focus and sustain attention. Simple tasks such as the discrimination and copying tasks used in the Paskewicz research which appear to lack inherent interest value require an external incentive to set the conditions which make it worthwhile to "pay attention" to the task. Children who draw the designs and who can notice the difference between their performance and the standard may not report this difference because it is easier not to make corrections, but to finish the task as quickly as possible, simply becouse there is no benefit to time spent in correction, but a definite benefit to finishing. Indeed, they analyzed the time spent in the copying task across levels of motivation and found that the children spent significantly more time on the task in the motivated condition. The reproduction-from-memory task appears to be more difficult and ego-involving. This results in the conditions in which full attention is already being paid to the task which cannot be increased by external reinforcers. After reviewing the studies in this section, it seems that the use of a reinforcer during the task increases performance and reduces errors. This is true for the discrimination and copying tasks. The reproductionfrom-memory task, however, does not seem to be affected by the application of a reinforcing condition. Ali and Costello (1971) have shown that when testing is proceding under motivating conditions and there is a change in the schedule of reinforcement such that reinforcement is 
received less frequently, this is seen as a punishment, the removal of a reinforcing condition. Therefore, all tasks should be reinforced and motivated in this manner, including the memory task, lest by contrast, the lack of the reinforcer be viewed as a punishment and reduce performance and increase errors.

Summary- Research has been presented pertaining to the need for redefinition of the terms used in visual processing assessments. Confounding variables and intercorreloted subcomponent tests do not allow for differentiol diagnosis in visual memory evaluations. Discrimination, visual-motor integration and visual memory are currently conceptualized and theoretically and operationally defined as separate abilities.

The establishment of norms for these variables has been shown to be clinically necessary if successful remediation is to take place. Research related to factors possibly affecting the collection of norms were presented.. Age, sex and intelligence group of the child as well as the sex of the examiner were presented as possible determinants of the error rate.

Motivation in test taking was discussed with specific regard to visual processing performance.. It was concluded that evaluations should be conducted under conditions of external reinforcement so that the validity of the measures remains uncontaminated by variations in the "paying attention" factor.

Such data collection allows a comparative look at the 
differential development of discrimination, integration and memory in elementary school children. 


\section{Chopter III}

Hypotheses and Methodology

\section{Introduction}

The primary purpose of the present research is to study visual memory abilities in elementary school children and to investigate those variables which affect the assessment of memory. To accomplish this task, and to provide for differential diagnosis of visual processing disabilities, a visual memory task was broken down into its component parts in order to establish developmental norms for discrimination, copying and reproduction-frommemory, visual-motor integration as well as memory. This approach provides for a differential assessment of the memory components in contrast to the traditional unitary measures.

The literature review pointed to the possible importance of a number of variables on discrimination, copying and reproduction-from-memory performance. Sex of the examiner, sex, age and intelligence category of the child were identified as variables which might affect performance and thus create the need for separate norms.

\section{Hypotheses}

Eypothesis One. Discrimination scores, copying scores and reproduction-from-memory scores will be significantly intercorrelated.

Hypothesis Two. Discrimination, visual-motor integration and visual memory will not be intercorrelated. Hypothesis Three. There will be no sex of child difference 
on ony of the three dependent measures: discrimination, integration and memory.

Eypothesis Four. Higher IQ children will make fewer errors in visual discrimination and visual memory than average IQ children.

Hypothesis Five. There will be no IQ differences on the measure of visual-motor integration.

Hypothesis Six. Older children will make fewer errors than younger children on discrimination, integration and memory. Hypothesis Seven. There will be no sex of examiner difference on any of the dependent measures: discrimination, integration, and memory.

\section{Methodology}

Subjects. Originally 400 elementary school children were pianned to participate in this normative study. Eighty of these children were to have come from the five to six year age groups. Even utilizing the assessment under motivating conditions, the attention span of the children in these groups could not be maintained for a period of time long enough to complete the evaluations. This is consistent with the literature describing the difficulties of evaluating five year olds, and thus explains the lack of norms for this age group on any measure of visual memory utilizing graphic responses. The revised sample eliminated the pre-school category resulting in the utilization of 320 children between ages six and ten.

The records of approximately 600 children were screened from which three hundred and twenty children 
were selected for inclusion on the basis of age, sex and IQ categories. All children were white and from a northern Rhode Island or southeastern Massachusetts public school system. The school districts are urban in nature reflecting two middle size cities in New England. The socioeconomic background was essentially middle class.

Age. The 320 children were selected for inclusion in one of eight age categories so that there were forty children in each six-month age group: $6-6 \%$; 6/2 -7 ; $7-7 \% ; 7 \%-8 ; 8-8 \% ; 8 \% 2-9 ; 9-9 \% ; 9 \not 2-10$.

Sex of the Child. Half of the total number of children selected for each treatment category were boys and half were girls.

Intelligence Level. Half of the total number of children selected for each treatment category were within the average IQ range and half were above average. Average IQ was defined as a score between 90 and 110. Above averoge was defined as a score above 110. Children whose IQ was below 90 were eliminated from this study since the norms are intended for diagnosing specific learning disabilities distinct from intellectual deficit. The IQ category was determined by the IQ score obtained either by review of the children's school records for group IQ data, or by administration of an individual intelligence test. Group scores were readily obtained for children obove the second grade. Children whose files did not contoin an IQ score were odministered a PPVT (Dunn, 1959): Sex of the Examiner. Half of the children for each 
treatment category were tested by female examiners; half were tested by male examiners.

A: $2 \times 2 \times 2 \times 8$ analysis of variance was used to examine these variables. There were 64 cells: each represented one level of sex of examiner, one level of sex of child, one level of IQ and one level of age. Each cell contained scores for five children.

Materials. The Revised Visual Retention Test (1963). was used for all the tasks. Form $C$ was used in comparing alternatives in the discrimination task. Form $D$ was used in the copying task. Form $\mathrm{E}$ was used in the reproductionfrom-memory task. These forms are equivalent and insure comparability of scores without the danger of practice effect by viewing the exəct same stimuli (Silverstein, 1962).

For the discrimination task the author prepared a set of comparison stimuli cards with six comparison cards for most of the Benton cards: one similar, and five different. The five different cards varied from the stondard cards along five error dimensions: omission, rotation, distortion, misplacement and size. The position of the similar card varied in each of the sets of comparisons with the standard. These 50 comparisons were designed to opproximate the possible errors in the other two test conditions. The discrimination task required indication of a same-different judgment in a paired comparison method. The standard was always in view together when the comparison stimuli were presented one at a time. This eliminated 
complex motor behavior, memory, and choice from among simultaneously presented alternatives as variables in the perceptual judgment. The same-different judgment could be communicated by the use of the words "same" or "different," or "yes" or "ho," or a shake of the head.

The copying task required the duplicating of the stimulus card from the Benton cards on $8 / 2 \times 5$ 5/2 wite paper. This is administration "C" in the manual (Benton, 1963).

The reproduction-from-memory task required the duplication of the stimulus card following a ten second exposure. This is administration "A" in the manual.

Frocedure.

Administration. All the children were tested in their schools with the exception of two children who were tested at home. They were seated at a desk or table with the examiner sitting next to them. They were given the following instructions:

This is a book that has pictures printed in it. (Point to the Benton). This book also has pictures in it, but I drew them. So if some look darker or lighter it's just because I'm o sloppy drawer. Sometimes the pictures will be the same, and sometimes the pictures will be different. I want you to let me know when the pictures are the same, or when they look different. Some of them ore tricky, so look corefully. For everyone you get right, I'm going to give you a penny to keep. OK, look at these two pictures and tell me if they are the same or if they ore different.

Following the response, if correct, the child received the penny paired with a social reinforcer, a smile ond a verbolization something like "good," cr "fine." 
Following the discrimination task, the child was told how many pennies were earned. The following instructions were then given::

Now. I have some more pictures here. Take this pencil, and draw the picture so that it looks like the one in the book. For every one you draw that looks like the one in the book, I'm going to give you another penny. OK, now draw this so that it looks the same.

The child was given a penny for every card that looked opproximately like the one in the book. Following this, these instructions were given:-

Now, this time I'm going to show you the picture for only ten seconds, then I'm going to take it away, and then I'm going to ask you to draw it for me. So look at the pictures very carefully, so when I take it awey you can draw it. For every one that looks like the one in the picture, I'm going to give you onother penny.

The picture was placed over the drawing paper so that the child could not begin to draw until the book was removed. The child was not shown the original again but was rewarded for every picture that approached the originol. Sometimes when the drowing wos so dissimilar to the original the child was shown it again as an explanation for his not receiving the penny.

Each subject received all three tests, discrimination, copying and reproduction-from-memory in the order indicated.

Scoring the Protocol. All records were scored by o reseorch assistant using Benton's scoring principles and guides as examples. Each stimulus cord was scored for the totol number of errors. The discrimination task 
was scored by the total number of incorrect judgments. Detailed instructions for the administration and scoring of the RVRT, as well as information about its use and development, can be found in the test manual.

On each test the errors were summed to yield the discrimination, copying and reproduction-from-memory scores. Visual-motor integration was obtained by subtracting the discrimination score from the copying score. The visual memory score was obtained by subtracting the copying score from the reproduction-from-memory score. 


\section{Chapter IV}

Results of Statistical Analysis

This chapter will present the results of the statistical analyses which were used to investigate the relationship between discrimination, copying (traditionally 8 visual-motor integration measure) and reproduction-frommemory (traditionally a visual memory measure); the re-lationship among discrimination, visual-motor integration and visual memory abilities measures; and the significance of the environmental variables: sex, age and IQ level of the child and sex of examiner.

\section{Hypotheses}

The statistical analysis used to test hypothesis one and two was a Pearson-Product Moment correlation. Table 1 presents the correlation matrix for these five dependent variables: discrimination, copying, reproduction-from-memory, visual-motor integration and visual memory. In determining significance for this study the .01 level of confidence was selected. Since the sample size is large, slight differences in scores would be considered significant; thus the more conservative level was used. Also, the .05 level results were considered too unreliable for purposes of norming.

Hypothesis 1. It was hypothesized that there would be a significant relationship among the traditional measures used to evaluate visual functioning in elementary school children. This was hypothesized since the abilities are intertwined: sopying as a measure of visual-motor integra- 
tion is confounded with discrimination; reproduction-frommemory is confounded by all the variables that comprise the copying skill. Therefore, a certain amount of errors in copying will be expected on the basis of discrimination errors contained within it, and reproduction-from-memory errors will vary with the errors in copying ability.

As shown in Table 1 , there is a significant intercorrelation of the traditional measures: discrimination, copying and reproduction-from-memory. This shows the clear relationship among these measures. In essence, these measures are measuring some factors in common, and not, as supposed, separate abilities. Therefore, hypothesis 1 was accepted.

Eypothesis 2. It was hypothesized that there would be no significant relationship among the measures developed for this study. Measures of discrimination, visuel-motor integration and visual memory were designed conceptually to reflect their independence as visual processes. The visual-motor integration score was obtained by eliminoting the effect of discrimination errors from copying errors. The visual memory score reflects the difference between errors obtained on the reproduction-from-memory task and those errors obtained on the copying task. Since the two measures are identical with the exception of the memory component, the visual memory score reflects a pure memory-for-designs ability.

Table 1 indicates the absence of a relationship among these measures. In essence, these measures are 
Table 1

Intercorrelations among Traditional and Derived Measures

\begin{tabular}{|c|c|c|c|c|}
\hline $\mathrm{D}$ & $\begin{array}{c}C \\
.524^{*} \\
\end{array}$ & $\begin{array}{c}\mathrm{R} \\
.425^{*} \\
\end{array}$ & $\begin{array}{c}\bar{V}-\overline{M I} \\
-0.069\end{array}$ & $\begin{array}{l}\text { VI } \\
.122\end{array}$ \\
\hline $\mathrm{C}$ & - & $.557^{*}$ & $.553^{*}$ & -0.070 \\
\hline $\mathrm{R}$ & $=$ & - & .198 & $.779 *$ \\
\hline $\mathrm{V}-\mathrm{MI}$ & - & - & - & .033 \\
\hline $\mathrm{VM}$ & - & - & - & - \\
\hline
\end{tabular}

${ }^{*} \mathrm{p}<.01$

D - Discrimination

C - Copying

$\mathrm{R}$ - Reproduction-from-memory

V-MI - Visual-Motor Integration

VM - Visual Memory 
assessing separate abilities. Thus, hypothesis two was accepted.

The means and standard deviations of the three dependent measures, discrimination, visual-motor integration and visual memory, are presented in Appendices A, B, and c.

A. $2 \times 2 \times 2 \times 8$ multivariate analysis as well as $2 \times 2 \times 2 \times 8$ analyses of variance was used to evaluate the effect of each of the assessment variables and their interactions on each of the dependent measures.

Eypothesis 3. It was hypothesized that there would be no significant sex differences on any of the three dependent measures: i.e., the mean error scores for boys would be the same as the mean error scores for girls. Table 2 presents the summary table for monova of the three dependent measures. Sex of the child was not found to be significant $(F=.4937$; df 256,1$)$;.. Table 3 presents the mean errors for each of the measures for boys and girls. Hypothesis 3 was accepted. Hypothesis 4. It was hypothesized that children in the higher IQ category would moke significantly fewer errors on the discrimination and memory measures. Table 2 shows the manova source table indicating a significant intelligence effect ( $F=7.123 ;$ df 1,256). Analysis of Tables 4 and 5 show that only the discrimination measure hod $\theta$ significant intelligence of the child effect (F. = 16.1581; df 1,256). Children who were in the higher IQ cotegory made significantly fewer errors thon the 


\section{Table 2}

Multivariate Analysis of Variance of Error Scores for the Three Dependent Measures for Sex, Age, \& IQ of the Child and Sex of the Examiner
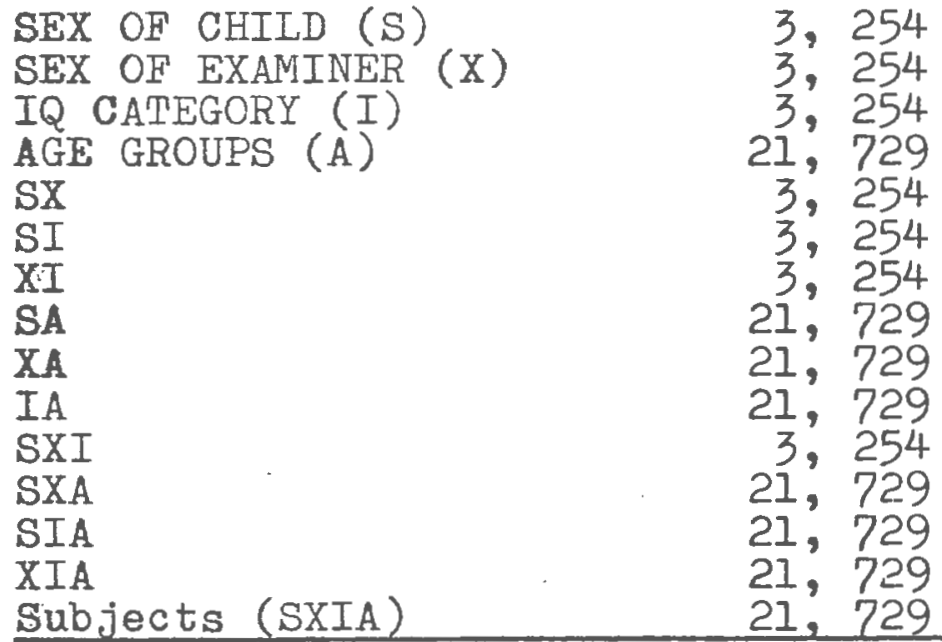
Table 3

Visual Processing Error Scores for Sex of Child

DISCRIMINATION

VISUAE-MOTOR INTEGRATION

\begin{tabular}{|c|c|c|}
\hline BOYS & \multicolumn{2}{|c|}{ GIRIS } \\
\hline 3.34 & 3.19 & n.s. \\
.343 & .368 & n.s. \\
8.06 & 7.73 & n.s. \\
\hline
\end{tabular}


Table 4

Analysis of Variance of Discrimination

Error Scores for Sex, Age and IQ of

the Child and Sex of Examiner $a$

\begin{tabular}{lccc} 
Source of Variation & $\begin{array}{c}\text { Degrees of } \\
\text { Freedom }\end{array}$ & $\begin{array}{c}\text { Mean } \\
\text { Squares }\end{array}$ & F \\
\hline SEX OF CHIID (S) & 1 & 1.7998 & 0.3146 \\
SEX OF EXAMINER (X) & 1 & 1.2500 & 0.2185 \\
IQ CATEGORY (I) & 1 & 92.4500 & $16.1581^{*}$ \\
AGE GROUPS (A) & 7 & 78.5196 & $13.7234^{*}$ \\
SX & 7 & 9.1123 & 1.5926 \\
SI & 1 & 5.5125 & 0.9634 \\
XI & 7 & 0.0125 & 0.00223 \\
SA & 7 & 7.4214 & 1.2971 \\
XA & 7 & 2.6571 & 0.4644 \\
IA & 7 & 7.1714 & 1.2534 \\
SXI & 1 & 7.2000 & 1.2584 \\
SXA & 7 & 4.9911 & 0.8723 \\
SIA & 7 & 4.4196 & 0.7724 \\
XIA & 7 & 4.1625 & 0.7275 \\
SXIA & 7 & 1.6212 & 0.2833 \\
Subjects (SXIA) & 256 & 5.7216 & \\
\hline
\end{tabular}

$* \mathrm{p}<.01$

- Fmax Test was performed $\fallingdotseq 187$. Homogenity of variance is assumed since no scale for 64 variances was available, although extrapolations place it non-significant. Robustness of anovas also indicate that probability of beterogenity is small. 
Table 5

Analysis of Variance of Visual Memory Error Scores for Sex, Age \& IQ of
the Child and Sex of the Examiner

Source of Variation

Degrees of Freedom

Mean

F Squares

\begin{tabular}{llrc}
\hline SEX OF CHIID (S) & 1 & 8.7781 & \\
SEX OF EXAMINER (X) & 1 & 95.7031 & 1.1601 \\
IQ CATEGORY (I) & 1 & 41.3281 & $12.6476^{* *}$ \\
AGE GROUP (A) & 7 & 59.1388 & $7.8617^{*}$ \\
SX & 1 & 16.6531 & 2.2008 \\
SI & 1 & 1.1279 & 0.1491 \\
XI & 1 & 37.1279 & $4.9066^{*}$ \\
SA & 7 & 10.9995 & 1.4536 \\
XA & 7 & 7.6531 & 1.0114 \\
IA & 7 & 3.9924 & 0.5276 \\
SXI & 1 & 34.4531 & $4.5531^{*}$ \\
SXA & 7 & 4.9171 & 0.6498 \\
SIA & 7 & 14.2493 & 1.8831 \\
XIA & 7 & 5.2064 & 0.6881 \\
SXIA & 7 & 9.4665 & 1.2484 \\
Subjects (SXIA) & 256 & 7.5669 & \\
\hline
\end{tabular}

$* * \quad p<.0 .1$
$* \quad p<.05$

Fmax $=85$, non-significant. Homogenity of variance assumption met. 
children in the average range of intelligence. The mean error score for the higher IQ children was. 2.73; the mean error score for the children in the average IQ category was 3.80 . The hypothesis was partially accepted, for discrimination.

Hypothesis 5. It was hypothesized that there would be no IQ differences on the measure of visual-motor integration. Table 6 shows that the variable of IQ was not significant $(F=0.5391 ;$ df 256,1$)$. Thus, the hypothesis was accepted. Hypothesis 6. It was hypothesized that older children would make fewer errors than younger children on all of the three measures. The source summary on Table 2 indicates a significant age variable $(F=8.479 ;$ df 7,256$)$. Analysis of the anova summaries on Tables 3,4 and 5 indicate significant age effect for discrimination ( $F=$ 13.7234, df 7,256) and visual memory $(F=7.8154$, df 7,256). Age was not significant at the .01 level for visual-motor integration ( $F=2.0610$, df 7,256$)$.

Figure 1 shows the trend for errors to decrease with age for discrimination scores, while Figure 2. shows the same for visual memory. It must be remembered, however, the visual-motor integration is a construct composed of the difference between copying and discrimination, corrected so that when the discrimination score was larger than the copying score, the difference was set at zero. Figure 3 represents the relative scores of discrimination, copying and visual-motor integration. Since discrimination and copying follow generally in the same pattern, 


\section{Table 6}

\section{Analysis of Variance of Visual-Motor Integration Error Scores for Sex, Age \& IQ of the Child and Sex of the Examinera}

Source of Variance

Degrees of Freedom

SEX OF CHILD (S)

SEX OF EXAMINER (X)

IQ CATEGORY (I)

AGE GROUP (A)

SX

SI

$X I$

$S A$

$X A$

IA

SXI

SXA

SIA

XIA

SXIA

Subjects (SXIA)

$* \mathrm{p}<.05$

Bmax = 81, non-significant. Homogenity of variance ossumption met.
Mean

F Squares

0.0498

0.7998

0.6123

2.3411

1.0125

4.0498

0.2000

0.8929

0.4857

0.2982

1.0125

2.8982

0.4214

0.6143

0.7410

1.1359
0.0438

0.7041

0.5391

2.0610*

0.8913

3.5654

0.1760

0.7861

0.4276

0.2625

0.8913

2.5515*

0.3710

0.5408

0.6524 


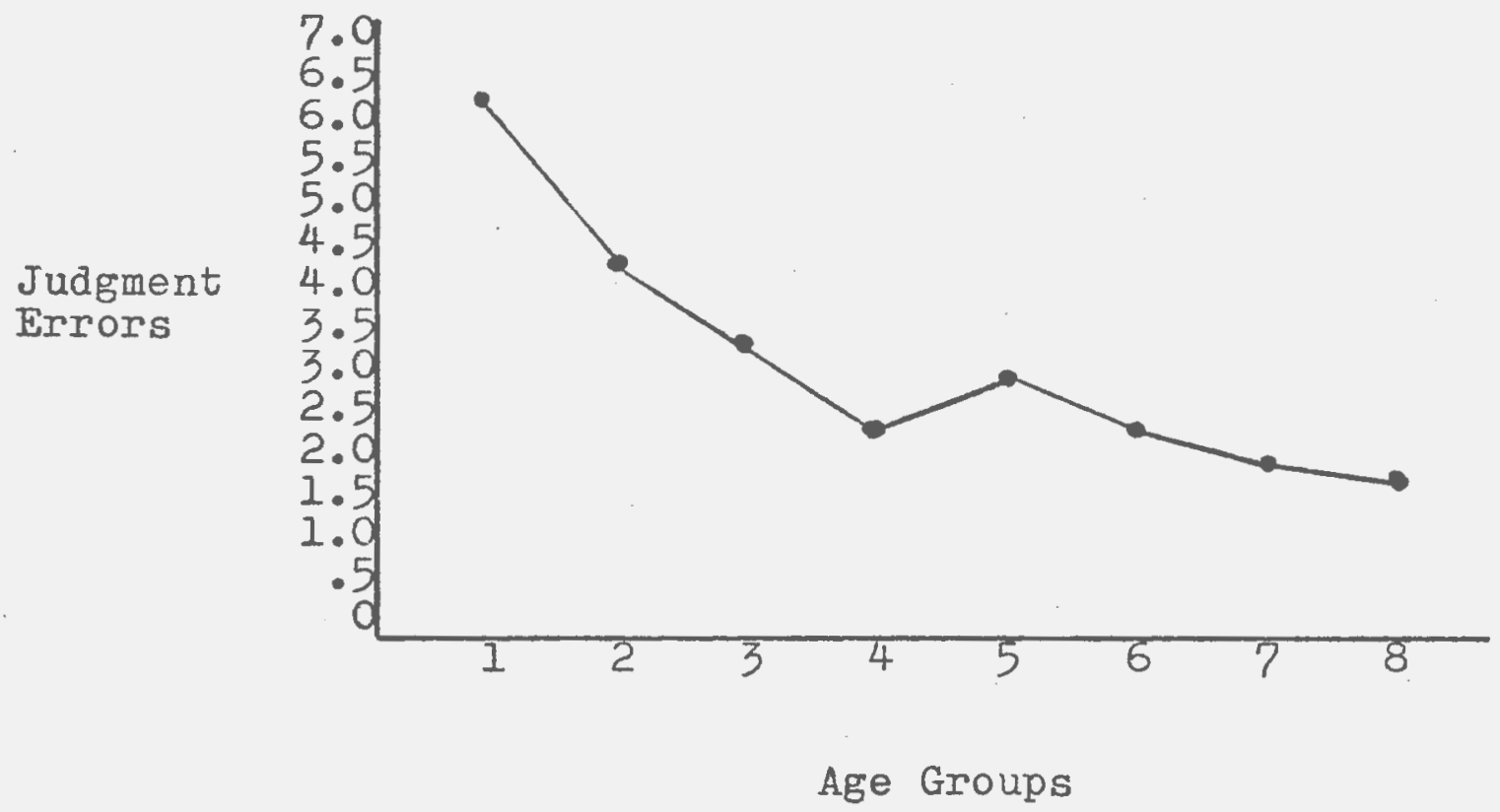

Figure 1. Pattern of scores for the Discrimination Task over Age (showing the decline of errors with increasing age).

Age Groups

1: $6-6 \%$

2: $6 k-7$

3: $7-7 \%$

4: $7 \%-8$

5: $8-8 \%$

6: $8 \% 2-9$

7: $9-9 \%$

$8:=9 \% 2-10$ 


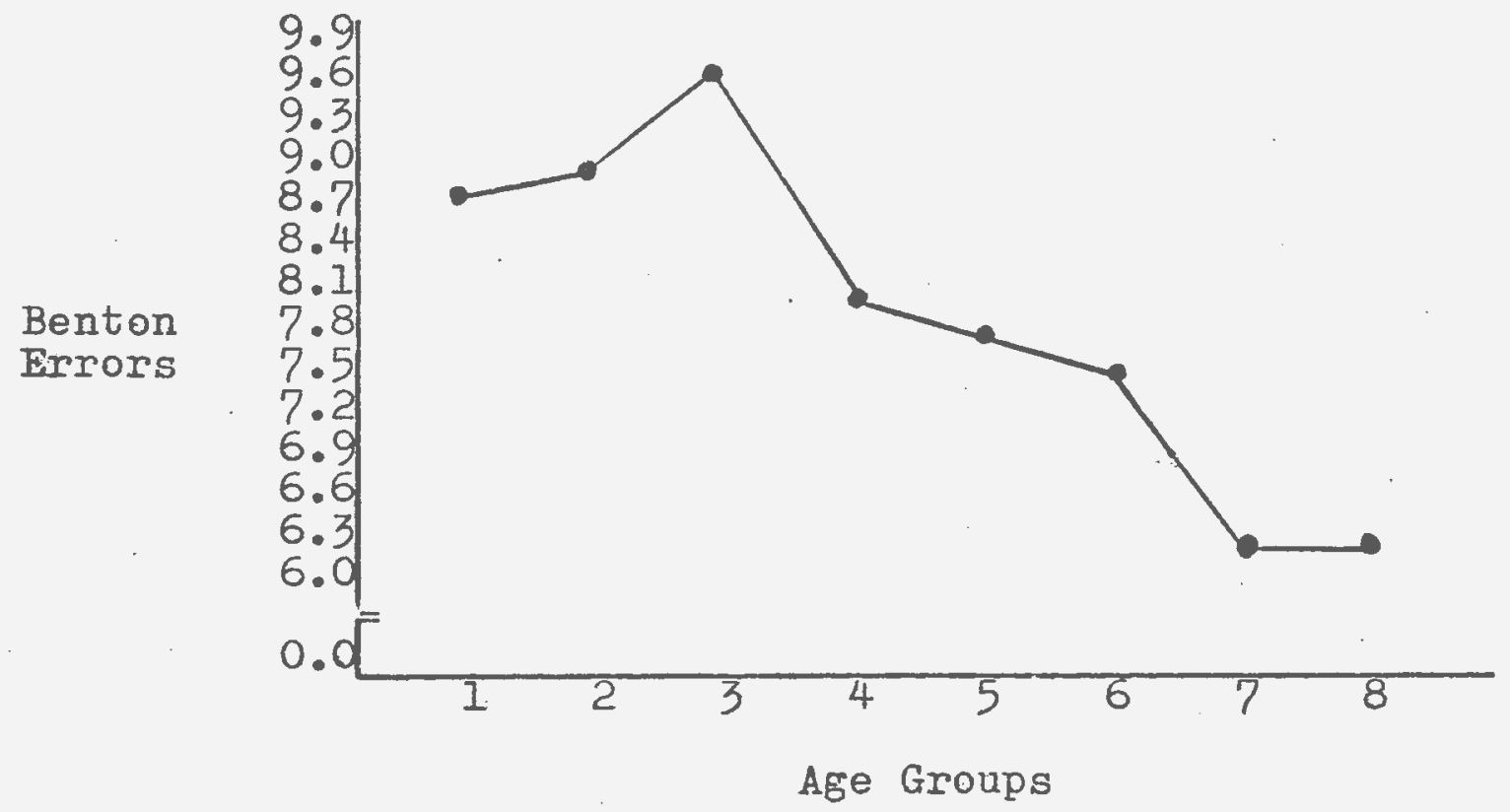

Figure 2. Pattern of scores for the Visual Memory Tosk over Age (showing the decline of errors with increasing age).

Age Groups

I: $6-6 \%$

$2: 61 / 2-7$

3: $7-7 \%$

4:: $7 \% 2-8$

5: $8-8 \not 2$

6: $8 \not k-9$

$7: 9-9 \%$

8: $9 \% 2-10$ 


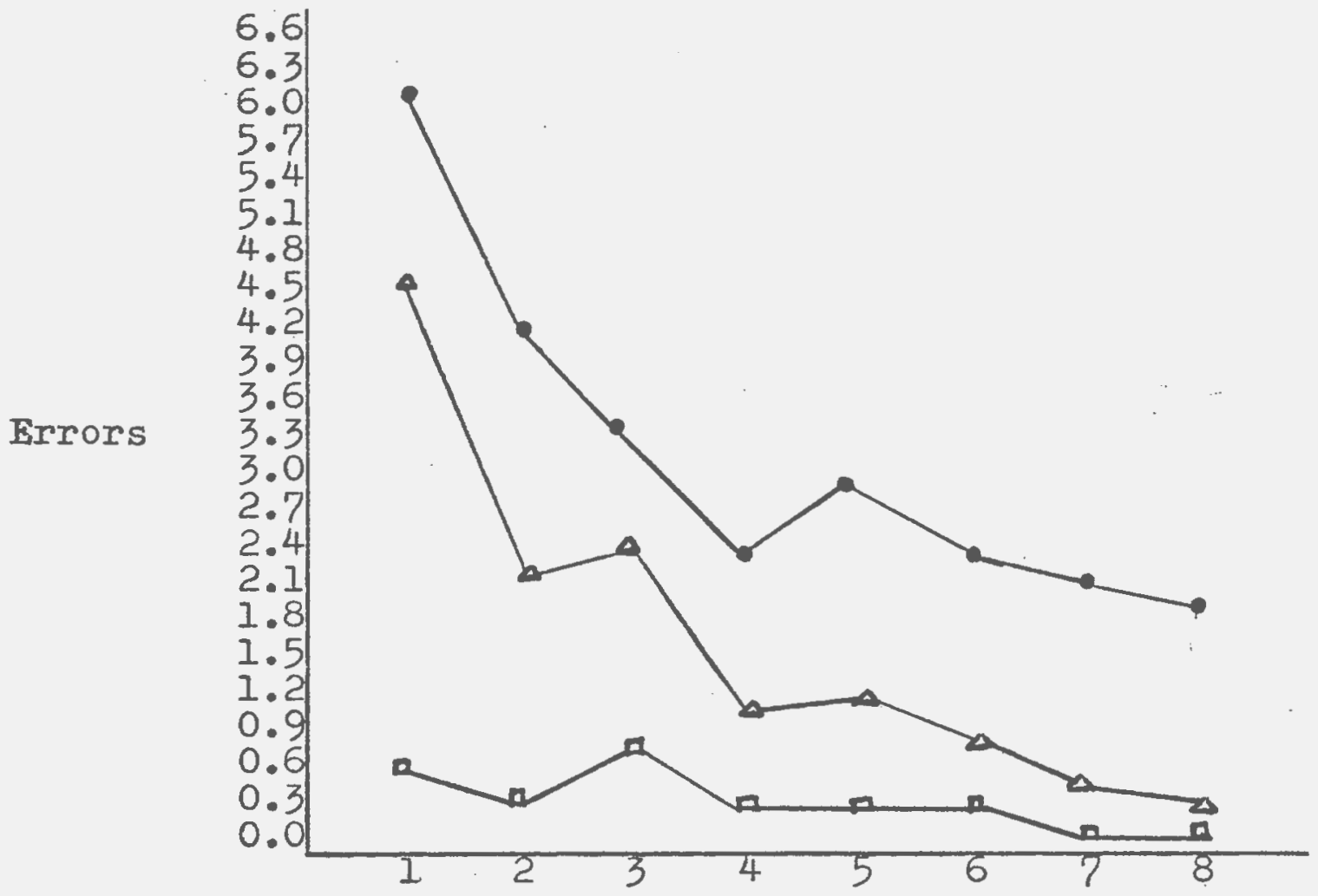

Age groups

Figure 3. Pattern of scores for the Discrimination, Copying and Visual-motor Integration over Age (showing that the similarity of pattern for discrimination and copying eliminates the age effect for the integration measure).

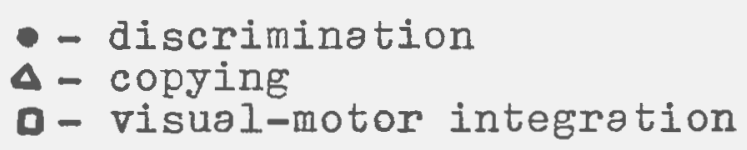

$1:: \quad 6-6 \%$

2: $6 \%-7$

3: $7-7 \%$

4: $7 \not / 2-8$

5: $8-8 \%$

6: $81 / 2-9$

7: $9-912$

8: $9 \%-10$ 
visual-motor integration which represents a difference score had no significance over age.

A Newman-Keuls test performed on the age variable in the discrimination measure shows that the 6 - $6 \%$ year old group differs from all the other groups. The 6\% - 7 year old group differs from the 9 - $9{ }_{k}$ year old group and the 9\% - 10 year old group. No other groups were different from each other. Table 7 shows the mean scores over age for the discrimination task.

A Newman-Keuls test was performed on the age variable in the visual-memory test. The order of the groups along the error dimension ranging from high to low was 7 - 7k, $6 \% 2-7,6-6 \% 2,7 \% 2-8,8-8 \%, 8 \% k-9,9 \% 2-10,9-9 \%$ 。 The results indicate that the 7 - 7/2 jear old group was different from the 8 and 9 year olds. The $6 \% 2-7$ year old group was different from the 9 year old groups. The 6 - 6/2 year old group was different from the 9 year old groups. The first three groups were not, however, different from each other. Table 7 shows the mean scores over age for the visual memory task. Thus, the hypothesis wos accepted for discrimination and visual memory.

In addition, since visual memory is a composite score, determined by the difference between reproduction-frommemory and copying, separate analyses of variance were performed on reproduction-from-memory and copying. Table 8 presents the source table for the copying measure, while Toble 9 presents the source table for the reproductionfrom-memory measure. Analysis of these tables shows that 
Table 7

Error Scores for Traditional and

Derived Measures over Age

\begin{tabular}{|c|c|c|c|c|c|c|c|c|}
\hline & 1 & 2 & 3 & 4 & 5 & 6 & 7 & 8 \\
\hline D & 6.275 & 4.20 & 3.42 & 2.42 & 3.00 & 2.47 & 2.22 & 2.12 \\
\hline C & 4.60 & 2.20 & 2.37 & 1.12 & 1.15 & 1.00 & .52 & .30 \\
\hline $\mathrm{R}$ & 13.30 & 11.17 & 12.05 & 9.22 & 8.75 & 8.45 & 7.02 & 6.65 \\
\hline$V-M I$ & .67 & .37 & .77 & .25 & .25 & .25 & .17 & .10 \\
\hline $\mathrm{VM}$ & 8.77 & 8.97 & 9.67 & 8.05 & 7.60 & 7.45 & 6.30 & 6.35 \\
\hline
\end{tabular}

D: Discrimination

C: Copying

R: Reproduction-from-Memory

V-MI: Visual-Motor Integration

VM:: Visual Memory 
Table 8

Analysis of Variance of Copying Error Scores for Sex, Age \& IQ of the Child and Sex of Examiner

\begin{tabular}{lccc} 
Source of Variation & $\begin{array}{c}\text { Degrees of } \\
\text { Freedom }\end{array}$ & $\begin{array}{c}\text { Mean } \\
\text { Squares }\end{array}$ & F \\
\hline SEX OF CHILD (S) & 1 & 0.1531 & 0.0374 \\
SEX OF EXAMINER (X) & 1 & 0.0029 & 0.0007 \\
IQ CATEGORY (I) & 1 & 25.8779 & 6.3139 \\
AGE GROUP (A) & 7 & 77.5210 & $18.9298 *$ \\
SX & 1 & 12.4031 & 3.0287 \\
SI & 1 & 6.9031 & 1.6857 \\
XI & 1 & 1.6531 & 0.4037 \\
SA & 7 & 2.4460 & 0.5973 \\
XA & 7 & 2.4960 & 0.6095 \\
IA & 7 & 5.7996 & 1.4162 \\
SXI & 1 & 4.7529 & 1.1606 \\
SXA & 7 & 5.6530 & 1.3804 \\
SIA & 7 & 6.6958 & 1.6350 \\
XIA & 7 & 1.0173 & 0.2484 \\
SXIA & 7 & 2.0463 & 0.4997 \\
Subjects (SXIA) & 256 & 4.0952 & \\
\hline
\end{tabular}

* $\mathrm{p}<.01$.

Fmax $=203$. Although no table for 64 variables is available, the cell variability appears to meet the assumption of homogenity of variance. 
Table 9

Analysis of Variance for Reproduction-from-

Memory Error Scores for Sex, Age \& IQ

of the Child and Sex of Examinero

Source of Variation

Degrees of Freedom

Mean

F Squares

\begin{tabular}{lrrr}
\hline SEX OF CHIID (S) & 1 & 10.8784 & 1.2593 \\
SEX OF EXAMINER (X) & 1 & 85.0786 & $9.8487^{*}$ \\
IQ CATEGORY (I) & 1 & 121.2786 & $14.0392^{*}$ \\
AGE GROUP (A) & 7 & 226.7889 & $26.2531^{*}$ \\
SX & 1 & 0.1536 & 0.0178 \\
SI & 1 & 14.8784 & 1.7223 \\
XI & 1 & 19.5034 & 2.2577 \\
SA & 7 & 17.6710 & 2.0456 \\
XA & 7 & 7.6282 & 0.8830 \\
IA & 7 & 6.7996 & 0.7871 \\
SXI & 1 & 19.5034 & 2.2577 \\
SXA & 7 & 12.4028 & 1.4358 \\
SIA & 7 & 9.3850 & 1.0864 \\
XIA & 7 & 55.6814 & 0.6577 \\
SXIA & 7 & 6.0967 & 0.7058 \\
Subjects (SXIA) & 256 & 8.6386 & \\
\hline
\end{tabular}

* p<.01.

Fmax $=49$, non-significant. Assumption of homogenity met. 
both Reproduction-from-memory and Copying have significant age effects. Figure 4 shows the relative positions of error scores for visual memory and its components: reproduction-from-memory and copying. This groph indicates that the difference between the measures of memory and the traditional measure of memory, i.e., reproductionfrom-memory, may be dramatic for the younger ages but less so with increasing age as copying errors decrease. A Newman-Keuls shows differences for the copying age scores in that the 6 - 6/2 Jeor old group is different from all the others. The $6 \% 3-7$ and the $7 \div 7 \%$ year old groups differ from the 9 year old groups. Table 7 shows the scores for copying over age.

A. Newmon-Keuls for the reproduction-from-memory measure indicates that the 6 - 6\% year old group differs from all groups except the 7 - 7\% year old group. The 7 - 7k year old group difiers from all other groups except the first group. The 6/2 - 7 year old group differs from the $7 \%$ - 8 year old group. The $7 \%$ - 8 jear old group differs from the 9 year old groups. The $8-8 \%$ Jear old group differs from the 9 - 9k year old group. Toble 7 shows the scores for reproduction-from-memory over вge.

Eypotbesis ?. It was hypothesized that sex of the examiner would not have an effect on any of the dependent measures. Toble 2 shows the significant manover $F$ for sex of examiner $(F=5.5169 ;$ df 1,256$)$. Analysis of the individual summary tables shows that for discrimination and visual-motor 


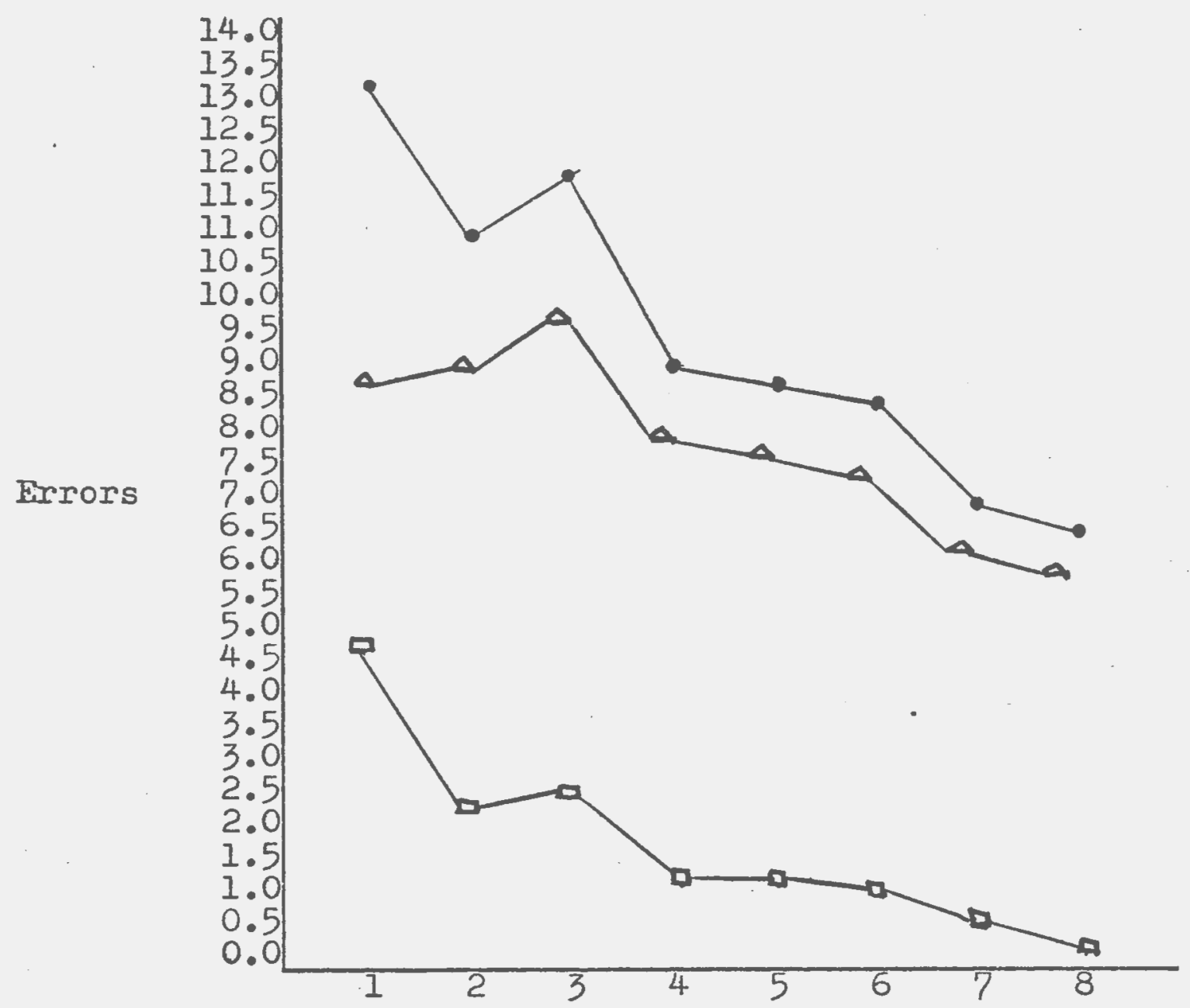

Age Groups

Figure 4. Pattern of scores for the Reproductionfrom-Memory, Copying and Visual Memory over Age (showing the effect of copying scores for the younger age groups).

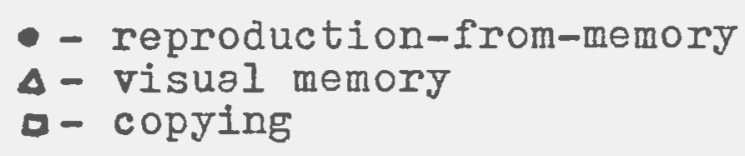

$$
\begin{array}{ll}
1: & 6-6 \% / 2 \\
2: & 6 \% 2-7 \\
3: & 7 \%-7 \% \\
4: & 7 \% 2-8
\end{array}
$$$$
\text { 5: } 8-81 / 2
$$$$
\text { 6: } 81 / 2-9
$$$$
7: 9-9 \%
$$$$
\text { 8: } 912-10
$$ 
integration there was no sex of examiner effect $(F=$ 0.2185, df 256,I; and $F=0.7041$, df 256, I respectively). However, sex of examiner was significant for the visual memory measure $(F=12.64$, df 1,256$)$. The mean scores for visual memory and those measures from which it is derived, reproduction-from-memory and copying, are presented in Table 10. Inspection of Figure 5 shows that reproductionfrom-memory is responsible for the sex of examiner effect. Table 9 indicates a significant sex of examiner effect for reproduction-from-memory, while Table 8 shows no such effect for copying.

An analysis of the error scores obtained by each of the examiners separately to determine whether the scores obtained by one individual examiner could account for this difference. The means for the examiners of both sexes were compared and found to be identical. All the male examiners had the same average error 7.4 , and both female examiners had identical values 8.4 . There was no individual variation on the part of any single examiner. Thus, the hypothesis of no effect was only partially accepted.

\section{Other Findings}

The hypotheses regarding the effect of assessment variables were primarily concerned with main effects. There were no interactions significant at the .01 level on any of the three dependent measures, discrimination, visual-motor integration or visual memory. There were, however, some main and interaction effects which were 
Table 10

Error Scores of Reproduction-from-Memory,

Copying and Visual Memory for

Sex of Examiner

\begin{tabular}{l|ccc} 
& Mole & Female & \\
\cline { 2 - 4 } $\begin{array}{l}\text { Reproduction-from- } \\
\text { Memory }\end{array}$ & 9.06 & 10.09 & $\mathrm{p}<.01$ \\
Copying & 1.66 & 1.65 & $\mathrm{n} . \mathrm{s}$. \\
Visual Memory & 7.40 & 8.44 & $\mathrm{p}<.01$ \\
\hline
\end{tabular}




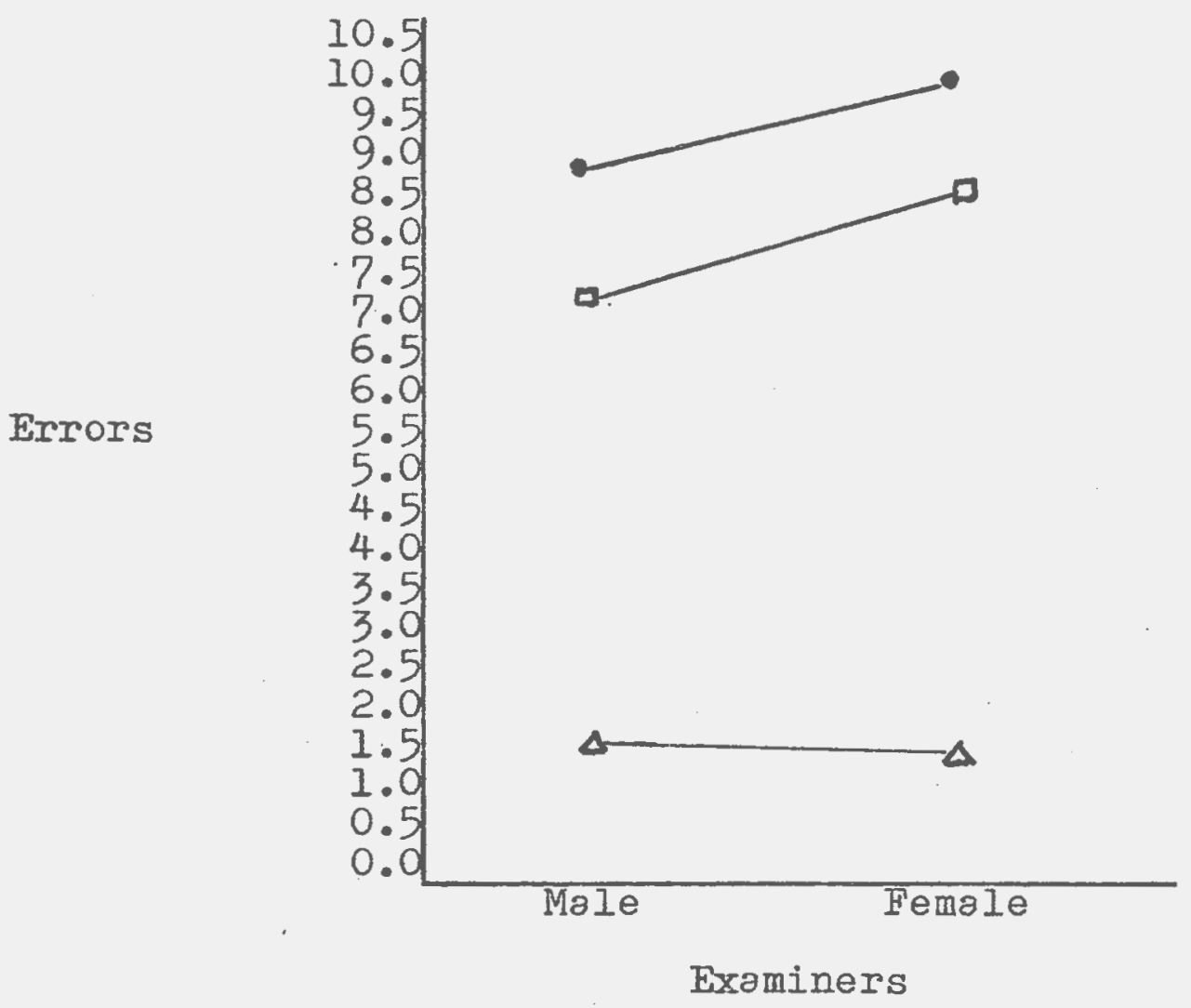

Figure 5. Pattern of error means for Reproductionfrom-Memory, Copying and Visual Memory for both sexes of examiner (showing that the primary effect of sex of examiner is within the reproduction-from-memory measure).

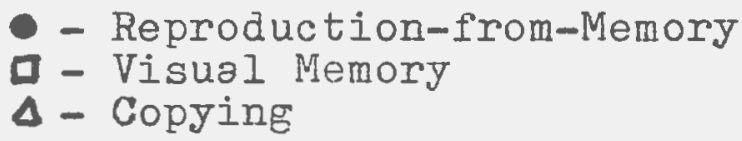


significant at the .05 level. Although they were not part of the study as such, and despite the fact that they did not attain the level of confidence set for the acceptance of results, they will be mentioned here as interesting findings. They will not be included in the norming aspect of this study since the chance that these findings are unreliable is too great to concretize in a set of norms.

The main effect of IQ category of children was found at the .05 level on the visual memory measure $(F=5.4617$, df 7,256). It was predicted that IQ. category would make o difference in the number of memory errors such that children with higher IQ's would make fewer errors than children with average IQ's. The mean error score for the above average group was 7.54 ; the mean for the average group was 8.26. The finding was in the expected direction.

The main effect of age was found significant at the .05 level on the visual-motor integration measure ( $F=$ 2.0610, df 1,256). It was predicted that age would make $\theta$ difference in the number of visual-motor integration errors such that older children would make fewer errors than children who were younger. This result confirmed the prediction. The mean error scores of visual-motor integration over age are presented in Table 7. The finding was in the expected direction.

The interaction effect of sex of the examiner and IQ category was significant at the .05 level for the visual memory measure $(F=4.9066$, df 1,256$)$. Figure 6 presents 


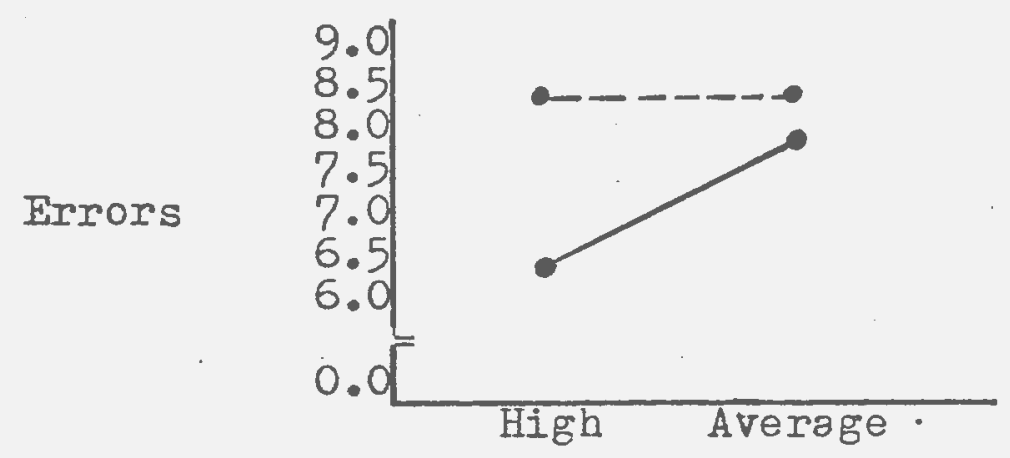

IQ Category

Figure 6. Pattern of scores for the Visual Memory showing the Sex of Examiner by IQ category interaction.

- - - female examiner

- male examiner 
the errors obtained for the visual memory task, showing the interaction of sex of examiner and IQ category. It appears that within the above average group, the errors obtained by male as opposed to female examiners are different. Within the average intelligence category, there appears to be no difference.

The interaction effect of sex of examiner, sex of the child and intelligence category was significant at the .05 level on the visual memory measure $(F=4.5531$, df 256,1). Figure 7 presents the errors obtained on the visual memory task, showing the interactions of sex of examiner, sex of child and IQ category. It appears that within the above average intelligence category, boys and girls tested by male examiners do not differ; boys and girls tested by female examiners do not differ; but children tested by males as opposed to females do differ in the error scores such thot children tested by femole examiners make more errors than children tested by male examiners. Within the average IQ category boys, tested either by moles or femoles, increase errors as expected. Girls tested by male examiners, however, tend to make more than the expected number of errors for the switch in IQ level. Also girls tested by feməle examiners tended unexpectedly to make fewer errors within the average group as opposed to the above average group.

The interaction effect of sex of examiner, sex of child and age was significant at the .05 level on the visual-motor integration measure ( $F=2.5515$, df 7,256). 


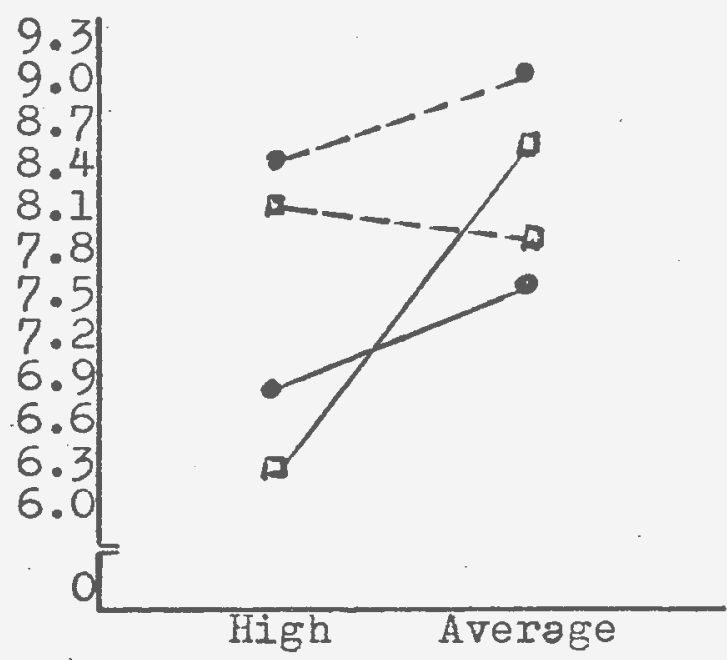

IQ Categories

Figure 7. Pattern of scores on the Visual Memory task showing the Sex of Examiner, Sex of Child and IQ Category Interaction.

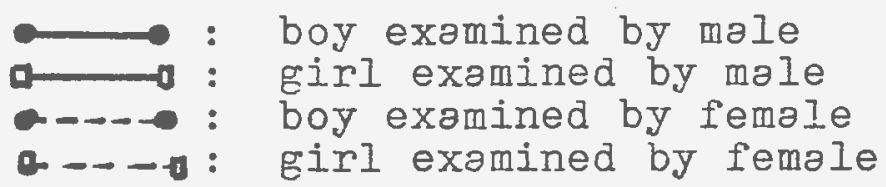


Figure 8 presents the errors obtained for the visualmotor integration task, showing the scores of boys tested by male and female examiners over the eight age groups. Figure 9 presents the errors obtained for the same task, showing the scores of girls tested by male and female examiners over the age groups. More variability appears to be associated with the younger children's performance, and while cross sex teams, girls tested by males and boys tested by females, appear to show a consistent pattern of a decrease in errors over age, boys tested by males and girls tested by females appear to show much more variability, especially within the third age group, the $7-7 \%$ year olds. 


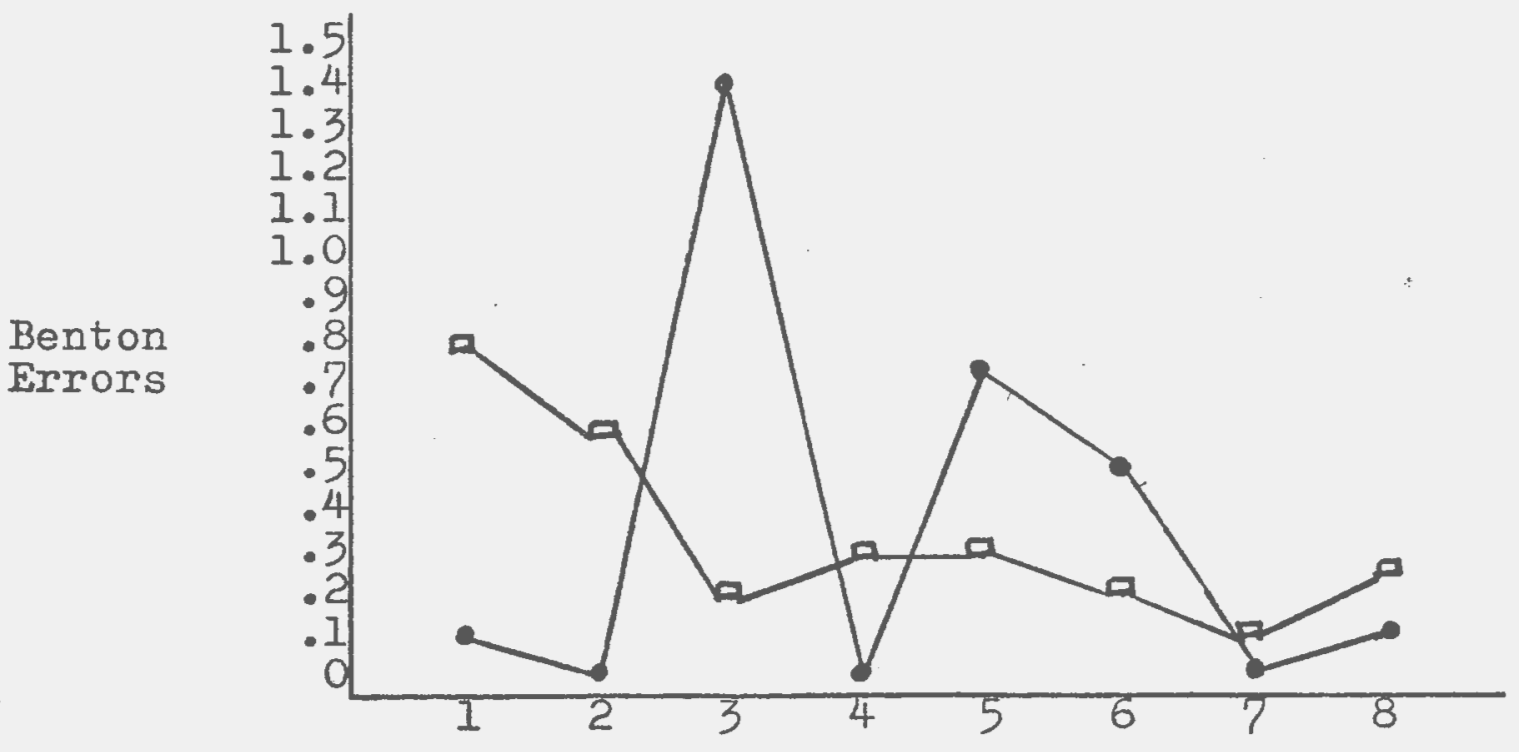

Age Groups

Figure 8. Pattern of scores for boys on the VisualMotor Integration task by Sex of Examiner (showing the differences among those tested by males and those examined by females).

Age Groups

$1: 6-6 \%$

2: $6 \% 2-7$

3: $7-7 \%$

4: $7 \% / 2-8$

5: $8-8 \%$

6: $8 \%$ - 9

$7: 9-9 \%$

8: $9 \not 2-10$

: examined by males Qـ : examined by females 


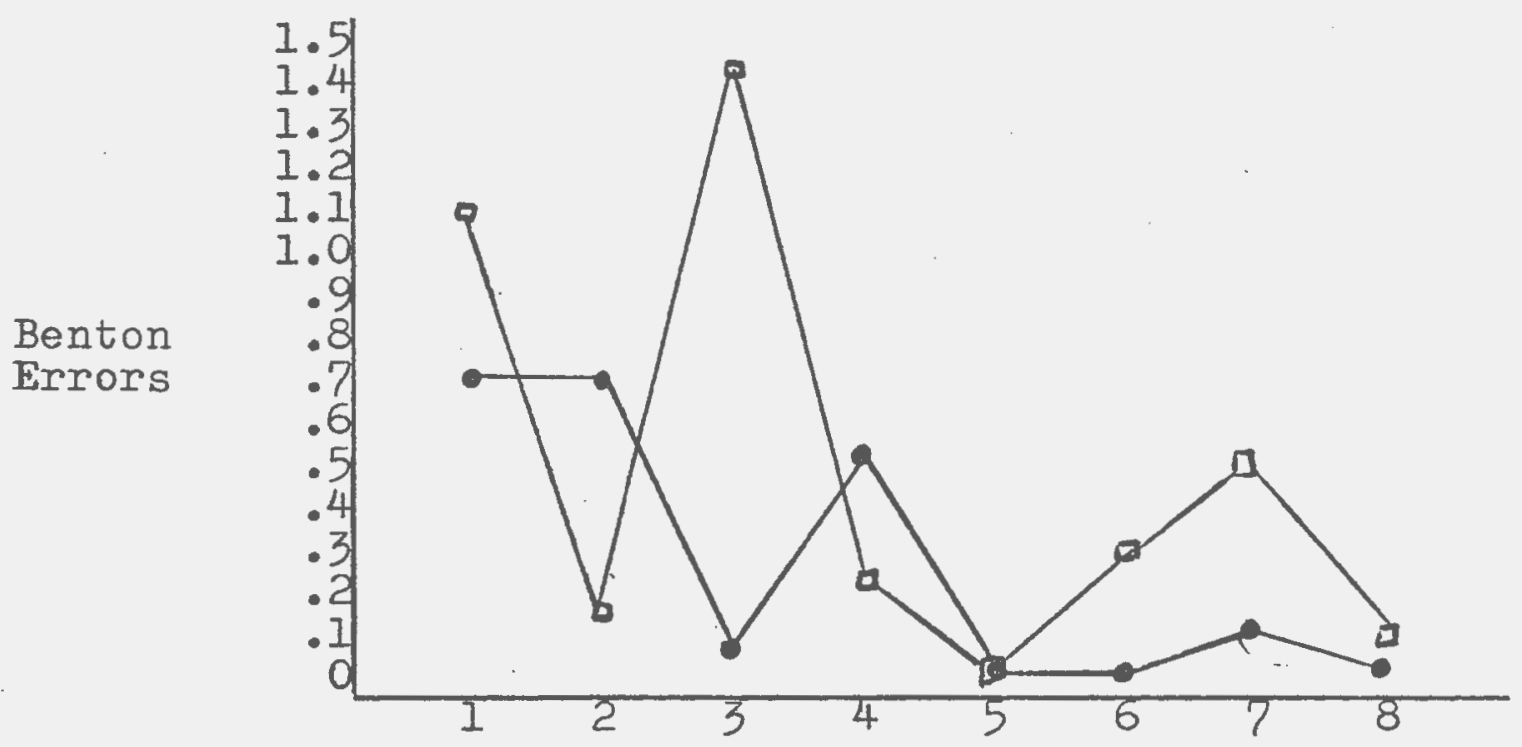

Age Groups

Figure 9. Pattern of scores for girls on the VisualMotor Integration task by Sex of Examiner (showing the differences among those tested by males and those tested by females).

Age Groups

$1: 6-6 \%$

2: $61 \%-7$

3: $7-7 \%$

4: $7 \% 2-8$

5: $8-8 \%$

6: $8 \not 2-9$

$7: 9-9 \%$

8: $972-10$

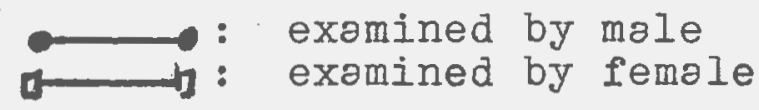




\section{Chapter V}

Conclusions

This chapter will include a discussion of the definitions of the terms used and the results of the intercorrelations between the measures both traditionally thought of and the ones presented in this study. This discussion will also include the effects of the vorious assessment variables on visual memory performance.' This will consist of the effects of sex, age and IQ: category of the child and sex of the examiner. It will also include a discussion of the separation of foctors within visual memory functioning and the effects of the independent variables on these measures.

\section{Measures of Visual Processing}

Praditional Measures. In the introductory chapter sets of definitions were presented so that the functional complexity of the measures traditionally used in visual memory research could be made clear, and new definitions could eliminate the confounding of measures. One of the basic hypotheses of the present study was that traditional measures used in the assessment of visual memory were confounded by factors and abilities which interfered with the collection of norms regarding visual memory. Such factors os discrimination and copying obility were identified as variobles which are measured concurrently with visual memory when tested in a paper and pencil situation. It was predicted that discrimination, copying and reproductionfrom-memory scores would be significantly related to each 
other. The correlation results show that this is the case, that the three measures are significantly related. This finding shows that what has been used in the past as a measure of visual memory is indeed confounded, and that other techniques must be developed if a measure of memory opart from other visual considerations is desired.

These results reconfirm the conclusions of Birch and Lefford (1967): who emphasized the multi-level functional complexity of these processes. These results are also in line with the results of the Newcommer and Hammill (1973) study, the Rosenblith (1965) study, as well as the work of Simpson (1974) who suggested that perceptual. functioning be separated into discrimination and integration. Wedell and Horns (1969) also found correlations between discrimination and copying. Only the results of Zach and Kaufman (1971) who found no relationship between discrimination and copying as measured by the Bender are at variance with the results found in the present study. They, however, criticized their own experiment on the basis of a lack of pure measure of discrimination.-

While these studies confined their attention to perceptual process and not with the memory factor, both perceptual measures correlated highly with reproductionfrom-memory. Thus, our measurement techniques and our conceptualization of them interfere with a pure assessment of visual memory. This conclusion leads us to seek out definitions and assessment techniques of visual memory not related to other perceptual processes. 
Derived Measures. The second basic hypothesis was that by utilizing the definitions set out in the introductory chapter, i.e., making distinctions between visual-motor integration and copying, and between reproduction-frommemory and visual memory, measures of various visual processes which were separate and unrelated to each other could be established. The results showed that among the measures of the concepts used in this study, discrimination, visual-motor integration and visual memory, there is no relationship, and that separate abilities were being measured. The use of this combination of tests indicates the clear possibility of differential diagnosis in the area of visual functioning in elementary school children. The use of these definitions as they have been set out eliminates confounding of measures and allows measurement of separate aspects of visual functioning.

In the work of Paskewicz and Weaver (1975), pilot project for this research, the three tasks of discrimination, copying and reproduction-from-memory were given to groups of second graders. Fifteen children took the discrimination test, another fifteen received the copying test, while another fifteen were administered the reproduction-from-memory task. The mean scores and analysis revealed that unmotivated children produced about twice os many copying errors as discrimination errors. In the motivated condition, the difference was .47 errors, 3 non-significant difference.

In this study, conducted only under a motivating 
condition, one similar to that used in the pilot study, the mean discrimination error for all children over all the age groups was 3.26. The mean copying error was 1.65 . So there was a reversal of the expected ronges of scores. A lower discrimination than copying score was expected. What occurred was the reverse. In many of the 64 cells, the children made more discrimination errors than copying errors.

One of the differences between the two research projects was that in the pilot work the children received only one task, either the discrimination, copying or reproduction-from-memory. It is possible that while copying errors remained approximately the same across the studies in the motivated condition ( 1.8 as compared with 1.6), because of the nature of the task children in this study were less careful since they knew that they would be tested on many tasks and could not place all their concentration and attention on the first task despite the presence of the reinforcement.

The fifty stimulus cards used in the discrimination test were designed to allow for the possibility of one of each type of scored error per card with some exceptions for the first few cards which had less possibilities for errors in copying, and correspondingly fewer for discrimination. The model of visual functioning suggests that discrimination is a separate ability, and is used in the act of copying to monitor what has been drawn, and to correct errors based on the judgments of similarity or difference. 
Zach and Kaufman (1971) found a lack of relationship between discrimination and copying, and explained this finding by suggesting that the measure of discrimination they had used was inadequate. They had used a measure utilizing a multiple-choice format which possibly called upon more visual factors than discrimination. This study utilized what they had suggested: a matching pairs combination. Results show a relationship between these measures as predicted, but unexpectedly found more discrimination errors than copying errors.

It is possible that since there were five times more cards than in the copying task, and since these fifty cards represented possibilities for errors rather than offering errors in proportion to their actual occurrence in copying tasks, the chance for making more errors than in copying increases. Even seeing the number of discriminations to be made, and knowing that there were more tasks to do than just this one, may have forced the children to rush and make mistakes they would not have ordinarily made. And indeed, there is the possibility that they may have been checking out the reinforcement contingency askIng the question what will happen if I answer incorrectly: will he/she give me the penny or not. It was observed that following incorrect judgments more apparent concentration and time was given to the stimuli which followed. Another possibility is that there is an experiential factor taking place in that these children do more copying in school and receive feedback on that skill, but are re- 
quired to do less formal discrimination work. The testing situation and procedures took for granted that the children would understand the same-difference directions and provided no practice for this task. So the number of errors for discrimination may be artificially high. Analysis of the discrimination results showed that on the average .7 errors occurred within the first few cards, or about 20 - 25 percent of the errors made.

Since test construction and environmental factors are considered to have resulted in the error scores for discrimination exceeding the scores for copying, all scores that followed this pattern were placed at zero. This means that all the copying errors could be explained on the basis of discrimination errors.

\section{Variables Affecting Assessment of}

\section{Visual Processing}

Sex of the Child. In the past, studies investigating sex differences among elementary school children on measures of visual perception have found no significant sex effect. This study reconfirms these consistent results. No significant sex differences were found on any of the measures used in this study, nor in the measures traditionally used. Boys and girls performed equally on tests of discrimination, copying and reproduction-from-memory, and on measures of visual-motor integration and visual memory. Norms for these measures then need not reflect sex differences.

IQ category of the child. In the past investigations in 
general have found that children with higher intelligence scores do better on tests of discrimination. The results of this study confirm this finding. Children in the higher IQ category make significantiy fewer errors than those witkin the average IQ range. Rosenblith (1965), in commenting on the relationship between IQ and discrimination errors, concludes that the relationship appears to come from the lowest IQ groups. Her study included varying numbers of children in IQ ranges beginning at 75 to over 134. The present study which eliminated children below average $I Q$ found a significant $I Q$ effect. On the average the higher IQ children scored over one less error. While the relationship in the present study did not reach significance $(r=-0.21)$, children in the higher category did significantly better than children in the average category. Thus, while the higher IQ group did better than the average IQ group, within the groups there was no relationship between IQ and discrimination. Results of this study, however, suggest that when reporting norms for discrimination, consideration be made to distinguish between IQ categories.

IQ category was significant at the .05 level in the measure of visual memory. A significant IQ effect was predicted from the literature review. Belmont and Butterfield (1969) suggest that the superiority of more intelligent people in visual memory performance relates to acquisition abilities. Haith (1971) concludes from his study with children that developmental changes in 
visual memory is not a factor of age changes in visual sensitivity, visual processing time, the ability to take in a large array of items, nor the ability to verbally encode these items. He suggests that the deficit be attributed to a lack of strategy for encoding the items to be remembered. This suggests mediation and/or production hypotheses in explaining the significant effect of IQ category on memory performance. Indeed the test used to differentiate IQ category for most of the younger children without IQ scores in their school files was the PPVT, a verbal IQ test based on naming and coding pictures verbally.

No effect for IQ category on the visual-motor integration measure was predicted. No significant effect was found. Issac (1971) reviewed the literature concerning the relationship between IQ and perceptual-motor functioning (copying), and found contradictory results. The present study found a non-significant correlation between copying and IQ $(r=-0.12)$. The correlation for visualmotor integration and $I Q$ was also non-signiflcant $(r=$ .03). It seems that the acquisition of visual input is offected by IQ but what happens to that input as it is associated with output is unrelated to intelligence. Age of the Child. Birch and Iefford (1967) found not only age differences in discrimination errors but also found that five year old children had developed a good discrimination ability and that errors fell off with increasing age and occurred infrequently at age nine. The 
results of Rosenblith (1965) also indicate an age effect. The results of this study confirm these findings. Indeed, subsequent results show that the groups that were different were the youngest groups, the six year olds. Even the younger six year olds were different from the older six year olds. No other groups were different.

It was also predicted that visual memory would vary over age. Investigators who have studied the development of visual memory over age have all agreed that memory increases with age. The results again confirm this finding. The findings of this present study, however, for the measure of visual-motor integration indicate no age effect. There are significont trends in development of both discrimination and copying: the skills that moke up the definition of integration. Their patterns are parallel 'such that their difference cancels out any developmental changes with age. It seems that when visual input is being integrated with motor output, and deficits in input and output are accounted for, the actual integration does not develop with age. The average integration error (.35) suggests that integration has little to do with errors in visual processing. Sex of the examiner. The sex of examiner was originally included in this study as a variable to check the possible sex of examiner, sex of child and age interaction. Rosenblith (1965) found a hint in confounded data that younger girls would perform better, i.e., make fewer errors, on a discrimination task when examined by a woman. 
This variable remained in this study after it was found unfeasible to continue to test the five year old group on the present measures. No main effect or interaction was found for sex of examiner on the discrimination task nor the visual-motor integration task. However, the finding of the significant effect for visual memory was surprising. Since visual memory is a composite measure utilizing the tests of copying and reproduction-frommemory, analysis of these measures was conducted to find where this effect was taking place. Reproduction-frommemory was the task affected by the sex of the examiner. Children examined by women did poorer on this task; the difference was over one point. Explanation of this result is speculative and may revolve around interference in the children's mediational abilities in acquisition since this is most affected by other variables, namely age and IQ of the child. It may be that since all the children had contact with only women teachers, the children experienced "test-performance anxiety": feeling selfpressure to do better when tested by a woman, fearing possible criticism for failure for less than expected results.

Summary. The development of children's ability to discriminate forms and to remember forms follows a familiar pattern of increase of ability with increase in age and IQ. Surprising was the lack of significance for any of the variables for the measure of visual-motor integration. For the purposes of norms, if the differences in obtained 
scores are non-significant for sex, age and IQ of the child as well as for sex of the examiner, the integration appears to be a constant factor. The mean score for errors in integration, the score obtained by the subtraction of the discrimination errors from the copying error score, was .35 errors. This score was obtained by setting at zero all the instances where the discrimination errors were larger than copying scores. However, even when negative scores were allowed and analysed, producing o second measure of visual-motor integration, there were no significant main or interaction effects. Appendix $D$ presents the means and standard deviations for visualmotor integration using the negative numbers, while Appendix E presents the anova summary table for visualmotor integration using the negative numbers. This means that typically when we thought of the development of visualmotor integration, or measured the effects of programs to develop this skill (Stodolsky \& Karlson, 1972), we were measuring copying abilities which are affected by age. The integration ability, made up of discrimination, and those skills that are involved in copying, may not be subject to developmental changes in elementary school, and if we are talking about integration we may be talking of a constant factor that adds little itself to the factors involved in poor memory performance. These statements ore tentative reflecting the qualifications surrounding the use of the discrimination measure. 


\section{Interaction effects}

Three interaction effects were found to be significant at the .05 level. Although these effects will not be considered in the establishment of norms, they are presented since they point to interesting results that might be replicated and investigated in more detail in the future.

There was a signifj.cant interaction between sex of examiner and IQ category for the visual memory measure. Within the high IQ group, the errors obtained by children examined by male and female examiners appear to differ, while no difference appears in the average intelligence group. Either above average children tested by males are making fewer errors, or high IQ children tested by females ore making more errors. Given the expected increase in errors with the average IQ category, the scores obtained by the male examiner going from 6.6 to 8.0 , from the above average to the average group, seems appropriate. The scores obtained by the female experimenters went from 8.42 to 8.46 ; no significant difference. If we are going to be consistent with the literature on memory and $I Q$ then it must be concluded that the women examiners are obtaining higher error scores than expected from the high IQ group. In all cases the examiners knew the IQ of the child.

Appropriate sex role conflicts are more salient for brighter children. In this culture it is more appropriate to perform for men whether the performer is a boy or a 
girl. Girls who bave high IQ's may not be encouraged by women to show their true copacity (measured by the errors produced for male examiners) as this may not be appropriate for girls to do well. Boys on the other hand may discount their performance since it is for a female examiner. In all cases children had the opportunity to see other children being tested by examiners of both the same and opposite sex. Boys being tested by women may not try as hard since they don't have to please a woman. This effect must be a strong one to overcome the effects of the built in motivation system:

An alternative hypothesis may revolve around a generalization of expectation from their classroom teacher, a woman. Their teacher may expect the bright children to do better, and the children carry this feeling into the testing situation where it interferes with their ability to remember. Such results are ripe for replication and hypothesis testing.

The interaction of sex of examiner, sex of child and IQ category on the visual memory measure further illuminates the problem. This interaction was significant at the .05 level. It appears that for female examiners testing high IQ children, both boys and girls did more poorly, perhaps for different reasons. Boys may well discount their performance as being one for a woman and therefore they don't have to perform well. Girls may be discouraged by the women from showing off their abilities. Girls may be punished by females for performing 
well. It is suggested that fear of success must start somewhere in childhood, perhaps as early as first grade.

Children, both boys and girls who are bright, when tested by males produce fewer errors. In this culture performance is directed at men who reward good performances especially in girls.

The shift to the average IQ children shows some interesting results.' Boys, tested by males or females, produce more errors, errors not unexpected on account of IQ differences. Girls, on the other hand, produce many more errors than expected for male examiners. They may be in some sense feeling the effects of punishment by males in general for not being smarter. Girls, on the other hand, make fewer errors in the average as opposed to the above average IQ group. This may reflect the fact that they are not feeling the effects of being punished by women in general, and thus can relax and perform with less anxiety interference. It must be remembered that all these conclusions are speculative and represent only ottempts to make some sense of surprising data, especially in a world sensitive to sexist issues.

The sex of child, sex of examiner, and age interaction for the visual-motor integration measure was significant at the .05 level. The variability of scores for same-sex relationship in the testing situation as opposed to cross-sex stable pattern of decrease of errors over age, shows no immediate pattern. The finding of more errors for the third age group, the 7 - $7 y_{2}$ year olds, 
when tested by a member of the same sex is curious, and perhaps reflects the change over from school as fun to school as the place to read and work and the reaction to that change differentially taking place in the situation of the testing over sex of examiner. This pattern should be watched in future studies to see if it is replicated. If so, investigation of the relationships in second grade may be interesting to follow up. 


\section{Chapter VI}

Implications of this Research

Implications for Diagnosis of Visuol Processing Abilities

Three Derived Measures. The main purpose of this research was to investigate visual memory abilities in elementary school children. The investigation focused on establishing separate and independent measures for visual processing abilities so that one could separate out the confounding factors in visual memory performances. This was important so that with this testing differential diggnosis could be carried out to examine what factors might be involved in poor visual memory performance. Decisions regarding the nature of the visual processing difficulty can now be made with regard to discrimination, visual-motor integration, visual memory as well as copying and reproduction-from-memory. Such differential diagnosis allows for the precise planning and management of remediation programs for the visually learning disabled, since for the first time correct diagnosis is perhaps available through use of these measures and these techniques. The main usefulness of this work will come in schools and clinics where referred children will be examined and a description of their visual processing abilities prepared to show strengths and weaknesses so that more effective programming might bring to focus on the specific nature of the disability os opposed to global notions of the presence of "perceptual" problems. 
Need for Revised Norms. Since this study utilized more exact measures of visual processing abilities, and since the testing was conducted under motivating conditions to bring out the capacity of the child as opposed to unmotivated performance, and since investigation was carried out to discover and identify those variables within the testing situation itself that may affect performance on these measures, new norms must be established to reflect normal functioning on these measures for varying significant conditions. The data coming from this present study sets up a series of norms for the measures used. These norms represent the mean functioning of children with consideration of their sex and age and IQ category as well as the sex of the examiner. Where these variables affected performance, they are reflected in the norms. In addition these norms were established by testing under motivated conditions. Future clinical testing should follow this practice to eliminate any sources of variance which could be accounted for by attention and motivation. It is not known how the variables would have interacted with the data under non-motivated conditions. Since these norms reflect data collected under such conditions, the mean errors listed vary from the Benton norms and in most cases the errors reported here are less. In addition, replacing the procedure of calculating the difference from the expected value and assigning diagnostic implications to the magnitude of the distance, the stendard deviation of each norm is listed. Errors greater 
than the mean plus one standard deviation are indicative of a child who has a weakness in this area.

Separate norms have been provided for Discrimination, Copying, Reproduction-from-Memory, Visual-Motor Integration ond Visual Memory. See Appendices F, G, H, I and J. Existence of such norms and attendant definitions provided in Chapter I give a base line against which the performance of any individual child may be compared. It is hoped that these norms will aid both in the judgment of who has a learning disability, i.e., identify disabled children, as well as provide differential diagnostic information as to the specific nature of the disability.

\section{Implications for Future Research}

The results of this study leave many questions open, and thus raise research possibilities..

Qualitative Anolysis. This project concentrated on the development of various aspects of visual perception in elementary school children. Discrimination, visual-motor integration and visual memory were studied by an evaluation of the quantitative aspects of errors produced in the context of vorious environmental assessment conditions. The errors in each of the measures considered could be further analyzed in qualitative terms. Possible error categories include stimulus omissions, distortions, rotations, misplacement and size change. Each of these error categories has its own developmental history with regard to the relative frequency of occurrence over age. Detailed listings of expected error rates at each age category within the 
assessment conditions would help in specific diagnosis within each dimension of visual functioning. Indeed comparisons of the magnitude and range category of the type of error could be made across the various visual processes. Such an analysis is in progress at the present time.

Sex of Examiner. The surprising finding of a significant sex of examiner variable as well as significant interactions ( $p<.05$ ) for sex of examiner by IQ category, and sex of child and sex of examiner and $I Q$ category bear further investigations and replications.

We assume the condition that elicits the more accurate performance reflects what the average child is capable of while the higher error rate produced by bright children for women examiners probably indicates the presence of interference. It may well be that intelligent children either are more sensitive to the conflicts revolving around their sex role status or the conflicts are more real for them:: picking up either achievement pressure or achievement "underplaying" from female examiners or generalizing that expectation from their experiences with the classroom teacher.

The interaction of bright children with female experimenters might be investigated in terms of generalization or familiarity. All the children in the present study had female teachers throughout their elementary school careers. A look at the sex of examiner variable with children who have been exposed to male teachers may 
produce different results. Also varying the degree of "Iiberated" attitudes and behavior on the part of the female teachers may play a part in this finding. Further replication of the unexpected sex of child, sex of examiner, IQ category interaction involving the reversal of the error rates expected for IQ categories (expecting brighter children to make fewer errors) in the case of girls tested by women, as well as the more thon expected increase in errors for girls tested by men within the average IQ range, appears necessary. It may well be that sex role expectations even in elementary school are beginning their effect on modes of interaction in the world involving showing competence and beginning of the fear of success.

Discrimination Task Redesigning. While the pilot study indicated fewer mean discrimination errors than copying errors for second graders (the difference being nonsignificant in the motivated condition, and thus essentiolly being zero), the present research noted greoter discrimination errors than copying errors. For reasons exploined in the last chopter, this reversal of expected résults reflects a disproportionate error chance using the current form of the discrimination test. The version of the test used in the present study made comparisons possible for all error categories for most of the stimuli. However, qualitative analysis of errors in copying might reverl fewer practical possibilities within the 6 to 10 year range. Such redesigning of the discrimination test 
in terms of better selection of the appropriate stimulus cards and the number to be used, makes possible a method of getting a better analysis of the children's average functioning. Studies should be carried out to determine the reliability of this new test instrument, as well as norming it for use in differential diagnosis.

Levels of reinforcement. The tests used in this research were administered utilizing motivating conditions, i.e., the children were reinforced with pennies during test performance. Such a procèdure significantly reduced errors on visual processing tests. However, this procedure while necessary to establish base rates of functioning while minimizing possible interfering factors such as lack of attention, is expensive and impractical for screening purposes within school districts where diagnostic evaluations are required in large numbers. The usefulness of this procedure as a clinical method with an individual person referred for evaluation is clear and its use recommended. Relevant literature reviewing the possible effectiveness and use of a variety of reinforcement techniques, including variations of the reinforcer (Kulberg, 1967), and secondary techniques, may provide us with information regarding more practical levels of reinforcement. The research of Paskewicz and Weaver (1975) indicating a significant reduction of errors in the motivated condition (promise ond immediate payment of pennies) for the discrimination and copying tasks is at variance with Issac's (1971) finding of no difference for the use 
of no motivation when defined as the promise of candy. This promise was, however, linked to improved performance over equivalent tasks, not on the exact same task. It is possible that this variation eliminates feelings of failure, and thus allows the reinforcers to be reinforcing. So it is possible that symbolic reinforcers and promises may work as well as concrete ones. Variations of reinforcers in level as well as dimension can rary with age of the child as well as other relevant socio-psychological factors. Levels of Intelligence. Benton published norms based on seven levels of intelligence. IQ category as a variable was significant only for the discrimination task. The literature on the relationship between IQ and discrimination errors indicated a possible difference between average and above average children. Finer differentiations of IQ within the discrimination test might reveal interesting results concerning their interaction, despite the lack of $\theta$ significant overall correlation $(r=-0.21)$ between discrimination scores and IQ for the total 320 children in this present study.

Norms for Retarded Children. This project was limited to average and above average children since the results, in terms of norms, were intended to be useful for diagnosing specific learning disabilities which excludes mentally retarded children. However, while retardation may lower average functioning, specific strengths and weaknesses for various functions are still present. Differential diagnosis of such abilities in MR children may help in the 
planning of more specific remediation. Therefore, extension of the norms to lower levels of IQ would be helpful.

Relationship with Non-Motor Tests. Recently interest in the non-motor test of visual processing has been increasing. Carroll (1974) has published a non-motor test of visual memory involving multiple-choice following exposure to a stimulus card: This method was introduced to compensate for the two major limitations of the reproduction technique: its impractability with younger $\mathrm{CA}$ and $\mathrm{MA}$ children as well as motor handicapped children. It is possible, however, that this type of memory assessment evaluates a different aspect of memory skills. In addition it is probable that errors associated with a weakness in differentiation ability and those associated with multiple-ctoice decision making confound these scores. It is important to discover whether these measures of visurl memory, the reproduction-from-memory minus copying type, the non-motor choice type and possibly the non-motor minus discrimination, are related and are measuring the same dimension of memory. If they are the easiest to administer, then they make the most sense for use. Prediction. The importance of accurate measures of visual memory results from its usefulness in predicting school related criterion, such as reading scores. Multipleregression equations with the measures of visual processing as the independent variables could be used to predict reading scores, the dependent variable. The 
relative importence of the visual skills could be determined. It is possible that some of these skills, while being considered a deficit, may not relate highly to academic functioning, so that remediol efforts directed at improving skills related to test measured may be irrelevant to improved school functioning, even if successful. This must be investigated. 
APPENDIX A

Discrimination Means and Standard Deviations 


\section{Appendix A}

Discrimination Means and Standard Deviations

$\begin{array}{llllllll}1 & 2 & 3 & 4 & 5 & 6 & 7 & 8\end{array}$

$\begin{array}{lllllllll}\mathrm{BMH} & 6.00 & 3.20 & 2.80 & 1.80 & 2.20 & 1.00 & 1.80 & 3.20 \\ & 4.15 & 1.33 & 3.65 & 0.75 & 2.23 & 0.89 & 0.40 & 1.72\end{array}$

$\begin{array}{lllllllll}\text { BMA } & 8.00 & 6.60 & 4.40 & 3.80 & 3.60 & 2.20 & 3.60 & 3.00 \\ & 5.48 & 2.94 & 2.06 & 1.33 & 2.80 & 0.98 & 1.02 & 1.41\end{array}$

$\begin{array}{lllllllll}\mathrm{BFH} & 5.60 & 4.40 & 2.80 & 1.80 & 1.00 & 2.40 & 1.60 & 1.20 \\ & 3.38 & 1.63 & 2.14 & 1.60 & 1.27 & 0.49 & 1.63 & 1.47\end{array}$

$\begin{array}{lllllllll}\text { BFA } & 5.20 & 5.40 & 3.40 & 3.00 & 4.00 & 1.80 & 3.80 & 2.40 \\ & 2.99 & 2.06 & 1.36 & 1.67 & 2.10 & 2.71 & 1.47 & 1.86\end{array}$

$\begin{array}{lllllllll}\text { GMH } & 5.20 & 1.00 & 4.00 & 0.80 & 3.20 & 2.60 & 3.60 & 2.20 \\ & 3.25 & 0.89 & 2.61 & 0.40 & 2.14 & 1.63 & 2.15 & 0.98\end{array}$

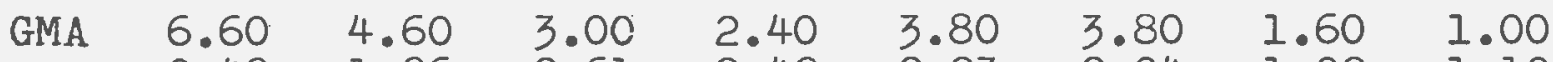

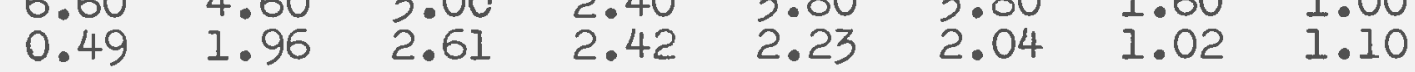

$\begin{array}{lllllllll}\text { GFH } & 5.40 & 3.40 & 3.20 & 2.20 & 2.20 & 2.60 & 0.60 & 2.40 \\ & 4.41 & 2.25 & 1.72 & 2.23 & 1.17 & 2.15 & 1.20 & 1.20\end{array}$

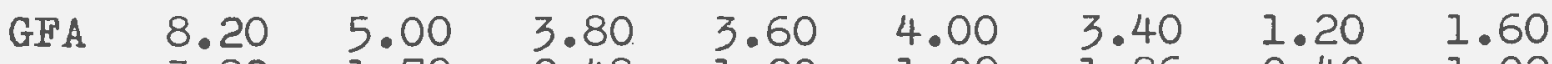

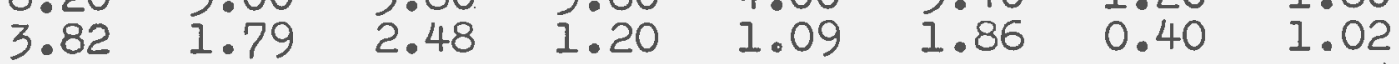

B: boys

G: girls

$\mathrm{M}$ : male examiner

F: female examiner

$H$ : above average (high) IQ

A: average IQ 
APPENDIX B

Visual-Motor Integration Means and Standard Deviations 
Appendix B

Visual-Motor Integration Means and

Standard Deviations

$\mathrm{BMH}$
0.0
0.0
2.00
0.0
0.80
1.00
0.0
0.0
0.0
0.0

$0.0 \quad 0.0 \quad 3.52$

0.0

0.75

0.63

BMA

$\begin{array}{lll}0.20 & 0.0 & 0.80 \\ 0.40 & 0.0 & 1.17\end{array}$

0.0
0.0

0.60
1.20

0.0

0.0

0.20

$\mathrm{BFH}$

$\begin{array}{ll}1.00 & 1.20 \\ 1.55 & 2.40\end{array}$

0.40

0.40

0.60

0.0

0.0

0.40

BFA

0.60

1.20

$$
0.0
$$

0.80

0.49

0.80

0.20

0.20

0.20

$0.0 \quad 0.20$

0.0

0.40

0.40

0.40

GMH

$\begin{array}{ll}1.00 & 0.80 \\ 1.55 & 1.17\end{array}$

0.0

0.40

0.20

0.0
0.0

0.20

0.0

0.40

0.40

GMA

$\begin{array}{llll}0.40 & 0.60 & 0.20 & 0.60 \\ 0.80 & 1.20 & 0.40 & 1.20\end{array}$

0.0

$0.40 \quad 0.0$

0.0
0.0

0.0

0.0

0.0

0.0

0.0

0.20

0.40

0.0

GFH

0.40

0.80

0.20

1.00
1.55

0.40
0.80

0.0

0.20

0.40

0.0

GFA

0.0

0.40

0.49

0.0

0.0

0.40

0.60

0.20 


\section{APPENDIX C}

Visual Memory Means and Standard Deviations 
Appendix C

Visual Memory Means and Standard Deviations

$\begin{array}{lllllllll}\mathrm{BMH} & 8.20 & 9.00 & 8.80 & 6.60 & 5.60 & 5.00 & 8.00 & 4.60 \\ & 2.79 & 3.03 & 3.97 & 2.50 & 1.50 & 1.67 & 1.41 & 2.42\end{array}$

$\begin{array}{lllllllll}\text { BMA } & 8.60 & 6.40 & 9.80 & 6.80 & 9.20 & 8.80 & 6.60 & 4.60\end{array}$

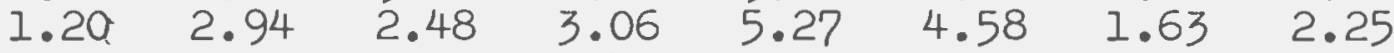

$\begin{array}{lrrrrrrrr}\mathrm{BFH} & 9.00 & 10.60 & 9.80 & 9.00 & 9.40 & 7.00 & 6.80 & 6.80 \\ & 0.89 & 1.96 & 2.93 & 1.55 & 2.50 & 2.19 & 2.56 & 1.33\end{array}$

$\begin{array}{lllllllll}\text { BFA } \quad 9.40 & 10.80 & 11.60 & 8.40 & 10.80 & 9.60 & 5.40 & 7.00\end{array}$

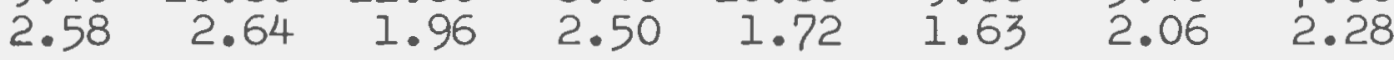

$\begin{array}{lllllllll}\text { GMH } & 8.00 & 5.60 & 7.60 & 5.40 & 6.00 & 7.20 & 4.60 & 6.20\end{array}$

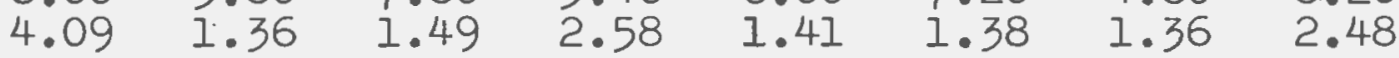

$\begin{array}{lllllllll}\text { GMA } & 9.40 & 9.40 & 10.20 & 10.80 & 6.60 & 6.80 & 6.60 & 8.20\end{array}$

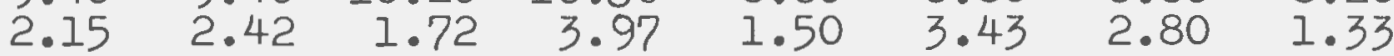

$\begin{array}{lllllllll}\text { GFH } & 9.40 & 10.60 & 11.20 & 9.80 & 6.80 & 7.40 & 6.00 & 5.20\end{array}$

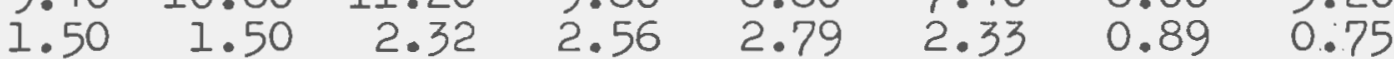

$\begin{array}{lllllllll}\text { GFA } & 8.20 & 9.40 & 8.40 & 7.60 & 6.40 & 7.80 & 6.40 & 8.20 \\ & 4.35 & 2.65 & 1.85 & 1.86 & 3.83 & 2.14 & 1.36 & 1.72\end{array}$

B: boys

G: girls

$\mathrm{M}:$ male examiner

F: female exəminer

$\mathrm{H}$ : above average (high) IQ

A: average $I Q$ 


\section{APPENDIX D}

Visual-Motor Integration Means and Standard Deviations Using Negative Numbers 


\section{Appendix D}

Visual-Motor Integration Means and Standard Deviations Using Negative Numbers

$\begin{array}{lrrrrrrrr}\text { BMH } & -2.60 & -2.20 & 0.00 & -1.40 & 0.40 & 1.00 & -1.60 & -2.80 \\ & 1.02 & 1.72 & 5.22 & 1.02 & 1.20 & 0.63 & 0.49 & 1.60 \\ \text { BMA } & -4.00 & -1.60 & -0.80 & -3.20 & -2.00 & -1.80 & -3.20 & -2.40 \\ & 4.24 & 1.86 & 2.79 & 1.72 & 3.52 & 0.75 & 1.33 & 2.15 \\ \text { BFH } & -0.60 & -3.80 & -1.00 & -0.60 & 0.00 & -1.80 & -1.20 & -1.00 \\ & 2.87 & 1.94 & 2.28 & 1.63 & 1.67 & 1.47 & 1.94 & 1.67 \\ \text { BFA } & -1.00 & -2.20 & -2.60 & -1.20 & -3.00 & -1.00 & -3.60 & -2.20 \\ & 2.97 & 1.83 & 1.20 & 1.33 & 2.28 & 2.53 & 1.36 & 2.16 \\ \text { GMH } & -2.00 & 0.60 & -2.40 & 0.20 & -2.40 & -2.20 & -2.40 & -2.00 \\ & 4.00 & 1.36 & 2.25 & 0.98 & 1.96 & 1.72 & 1.50 & 1.27 \\ \text { GMA } & -0.80 & -2.20 & -1.80 & -1.00 & -3.40 & -1.60 & -1.40 & -0.80 \\ & 1.72 & 3.31 & 1.72 & 2.90 & 2.50 & 1.86 & 1.36 & 0.75 \\ \text { GFH } & -1.60 & -2.00 & -0.20 & -1.60 & -2.00 & -2.20 & -0.20 & -2.20 \\ & 2.42 & 2.19 & 2.48 & 2.73 & 1.41 & 2.14 & 1.47 & 0.98 \\ \text { GFA } & -1.20 & -2.60 & 0.40 & -1.60 & -2.40 & -2.20 & 0.00 & -1.20 \\ & 5.56 & 2.06 & 3.61 & 1.02 & 1.36 & 2.93 & 1.41 & 1.33\end{array}$

B: boys

G: girls

M: male examiner

F: female examiner

$\mathrm{H}$ : above average (high) IQ

$A$ : average IQ 


\section{APPENDIX E}

Analysis of Variance for Visual-Motor Integration Using Negative Numbers for Sex, Age and IQ of the Child and Sex of the Examiner 
Appendix E

Analysis of Variance for Visual-Motor Integration Using Negative Numbers for Sex, Age and IQ of the Child and Sex of the Examiner

\begin{tabular}{lcrc} 
Source of Variation & $\begin{array}{c}\text { Degrees of } \\
\text { Freedom }\end{array}$ & $\begin{array}{r}\text { Meon } \\
\text { Squares }\end{array}$ & $F$ \\
\hline SEX OF CHIID (S) & 1 & 0.5281 & 0.0794 \\
SEX OF EXAMINER (X) & 1 & 0.0029 & 0.0004 \\
IQ CATEGORY (I) & 1 & 10.8779 & 1.6347 \\
AGE GROUP (A) & 7 & 4.6531 & 0.6993 \\
SX & 1 & 2.2781 & 0.3423 \\
SI & 1 & 14.0281 & 2.1081 \\
XI & 7 & 0.0281 & 0.0042 \\
SA & 7 & 9.7067 & 1.4587 \\
XA & 7 & 4.6817 & 0.7035 \\
IA & 7 & 6.3281 & 0.9510 \\
SXI & 7 & 0.5281 & 0.0794 \\
SXA & 7 & 9.4995 & 1.4276 \\
SIA & 7 & 7.3638 & 1.1066 \\
XIA & 7 & 4.0924 & 0.6150 \\
SXIA & 256 & 2.4208 & 0.3638 \\
Sub jects (SXIA) & & 6.6544 & \\
\hline
\end{tabular}




\section{APPENDIX F}

Norms for Discrimination Measure 
Appendix F

Norms for the Discrimination Measure

Age:

IQ Category

\begin{tabular}{l|ll}
\multicolumn{1}{c|}{} & $90-110$ & Above 110 \\
\cline { 2 - 3 } $6-6 \%$ & $7.00(3.96)$ & $5.55(3.94)$ \\
$7-7 \%$ & $5.40(2.42)$ & $3.00(2.08)$ \\
$7 \%-8$ & $3.65(2.30)$ & $3.20(2.75)$ \\
$8-8 \%$ & $3.20(1.85)$ & $1.65(1.57)$ \\
$8 \%-9$ & $3.85(2.21)$ & $2.15(1.98)$ \\
$9-9 \%$ & $2.80(2.22)$ & $2.15(1.63)$ \\
$9 \%-10$ & $2.55(1.61)$ & $1.90(1.89)$ \\
\hline
\end{tabular}

- Mean and (Standard Deviation) 
APPENDIX G

Norms for Visual-Motor Integration Measure 
Appendix G

Norm for Visual-Motor Integration Measure ${ }^{8}$

$0.35(1.06)$

a Mean and (Standard Deviation) 
APPENDIX $\mathrm{H}$

Norms for Visual Memory Measure 
Appendix $\mathrm{H}$

Norms for the Visual Memory Measure ${ }^{2}$

Age:

Sex of Examiner

\begin{tabular}{l|cr} 
& mole & female \\
\cline { 2 - 3 } $6-6 \not k$ & $8.55(2.89)$ & $9.00(2.79)$ \\
$6 \not k-7$ & $7.60(3.09)$ & $10.35(2.37)$ \\
$7-7 k_{2}$ & $9.10(2.86)$ & $10.25(2.69)$ \\
$7 \not k-8$ & $7.40(3.79)$ & $8.70(2.36)$ \\
$8-8 \not k$ & $6.85(3.33)$ & $8.35(3.44)$ \\
$8 \not k-9$ & $6.95(3.47)$ & $7.95(2.37)$ \\
$9-9 k_{2}$ & $6.45(2.31)$ & $6.15(1.95)$ \\
$9 \not k-10$ & $5.90(2.69)$ & $6.80(1.99)$ \\
\hline
\end{tabular}

- Mean and (Standard Deviation) 


\section{APPENDIX I}

Norms for the Copying Measure 


\section{Appendix I}

Norms for the Copying Measure

Age :

$6-6 \%$

$6 \not 2-7$

$7-7 \% / 2$

$71 / 2-8$

$8-8 \not 2$

$8 \not z-9$

$9-9 \%$

$9 \% 2-10$
Mean and Standard Deviation

$$
\begin{aligned}
& 4.60(3.75) \\
& 2.20(2.43) \\
& 2.38(2.33) \\
& 1.13(1.13) \\
& 1.15(1.51) \\
& 1.00(1.47) \\
& 0.53(1.01) \\
& 0.30(0.52)
\end{aligned}
$$


APPENDIX J

Norms for the Reproduction-from-Memory Measure 


\section{Appendix J}

Norms for the Reproduction-from-Memory Measure

\begin{tabular}{|c|c|c|}
\hline & $90-110$ & Above 110 \\
\hline $6-6 / 2$ & $13.90(1.2 .85)$ & $11.60(3.89)$ \\
\hline $6 \% 2-7$ & $11.60:(3.06)$ & $8.60(3.44)$ \\
\hline $7-7 \psi_{2}$ & $12.40 .(2.41)$ & $10.40(2.88)$ \\
\hline $7 \not k-8$ & $9.80 .(4.37)$ & $6.70(2.58)$ \\
\hline $8-8 \not k$ & $8.90(4.53)$ & $7.50(2.27)$ \\
\hline $81 / 2-9$ & $9.10(3.84)$ & $7.30(1.95)$ \\
\hline $9-9 \not k 2$ & $6.90(2.51)$ & $7.80(3.85)$ \\
\hline $9 k-10$ & $6.80(2.78)$ & $5.70(2.67)$ \\
\hline
\end{tabular}

$$
\begin{aligned}
& 6-6 \not z \\
& 6 \not z-7 \\
& 7-7 \not k \\
& 7 \not k-8 \\
& 8-8 \not k \\
& 8 \not k-9 \\
& 9-9 \not k \\
& 9 \not z-10
\end{aligned}
$$

$90-110$

$14: 10(3.45)$

$12.90(3.78)$

$12.50(2.27)$

$10.10(2.85)$

$9.90(3.35)$

$9.70(1.83)$

$6.60(2.37)$

$7.90(2.38)$
Above 110

$13.60(3.24)$

$11.60(2.32)$

$12.90(2.92)$

$10.30(2.31)$

$8.70(3.06)$

$7.70(3.23)$

$6.80(2.06)$

$6.20(1.48)$ 
115.

APPENDIX $\mathrm{K}$

Raw Data 
Subject*

11111

11112

11113

11114

11115

11211

11212

11213

11214

11215

11121

11122

11123

11124

11125

11221

11222

11223

11224

11225

11131

11132

11133

11134

11135

11231

11232

11233

11234

11235

11141

11142

11143

11144

11145

11241

11242

11243

11244

11245
Disc.

3
2
3
12
10

18

9
5
2

4
3
1
3
5

10

10

6

3
4

0

10

2

1

1

7
6
5
2
2

2

2
1
1
3
2

4

5

4

2
3
Copying Repro.

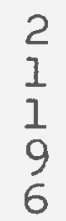

7

13

6

19
15

16
15
11
13
8

6

15

9

8

12

4

0
1

15

13

13

9

11

10

13

14

10

3
2
5
5
3

17

13

14

12

11

19

1

0

0

0

0

1

0

?
9
3
6
8
9

5
12
8
10
2 
Subject*

11151

11152

11153

$1 I 154$

11155

11251

11252

11253

11254

11255

11161

11162

11163

11164

11165

11261

11262

11263

11264

11265

11171

11172

11173

11174

11175

11271

11272

11273

11274

11275

11181

11182

11183

11184

11185

11281

11282

11283

11284

11285
Disc.

0
2
3
0
6

9

1

3
3

0

2

1

0

2

3
3
3
1
0

1
2
2
2
2

2
5
4
3
4

3

4

0

5

4
5
3
1
2
Copying

1
1
4
2
5

1

0

6

1
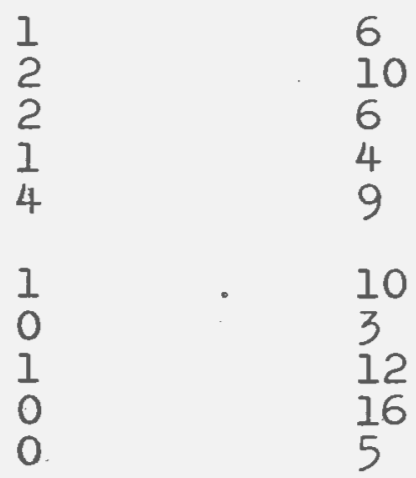

0

0

0

0

1

1
0
0
0
1

0

1

1

0

0

0

0

0

I
Repro.

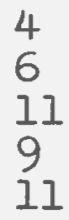

18

13

2

12

6

10

6

4

9

10

12

16

6

18

9
$?$

9
5
6
5
10

5
6
$?$
0
7

5
5
4
10
2 
Subject*

12111

12112

12113

12114

12115

12211

12212

12213

12214

12215

12121

12122

12123

12124

12125

12221

12222

12223

12224

12225

12131

12132

12133

12134

12135

12231

12232

12233

12234

12235

12141

12142

12143

12144

12145

12241

12242

12243

12244

12245
Disc.

10

5

2

2

5
3
8
1
9

6

6

2

5
3

3
4

6

5
9

2
1
2
2
7

2
2
5
3
5

0

2

0

4
3

2
5
1
5
2
Copying

6

2

6

1

5
6
2
1
7

1

0 .

1

0

1

3
4
3
1
5

4

0

1

2

0

0.

$\frac{1}{2}$

1

1
2
1
1
1

1
2
0
3
3
Repro.

14

11

14

11

16

13

12

20

15

10

9

10

12

13

14

15

8

20

13

10

16

8

11

11

11

16

14

10

9

10

9

10

6

11

11

16 
Subject*

12151

12152

12153

12154

12155

12251

12252

12253

12254

12255

12161

12162

12163

12164

12165

12261

12262

12263

12264

12265

12171

12172

12173

12174

12175

12271

12272

12273

12274

12275

12181

12182

12183

12184

12185

12281

12282

12283

12284

12285
Disc.

0

0

0

3
2

6

1
5
2
6

0

4

1

4

1

5

5

1
1
0
4

0

4

1
5
2
0
3

0

1

0

0

0

3

0

1

0 .

0

$\frac{1}{2}$

0

0

9

10

14

8

11

14

11

9

13

7
5
14
7
5

8

12

10

10

12

3

11

7

8

3
5
9
6
5

7
5
9
6
8

I

0

0 .

0

0

1 
Subjects*

$21111]$

21112

21113

21114

21115

21211

21212

21213

21214

21215

21121

21122

21123

21124

21125

21221

21222

21223

21224

21225

21131

21132

21133

21134

21135

21231

21232

21233

21234

21235

21141

21142

21143

21144

21145

21241

21242

21243

21244

21245
Disc.

0

9

7

3
7

7
6
7
7
6

0

2

1

0

2

4

4

5

1

3
6

8

$\frac{1}{2}$

1

8

2

3

1

0

1

1

1

2
0
$?$
1
2
Copying

$\frac{1}{4}$

11

0

0

6

8

4

?

0

1

1

3
3

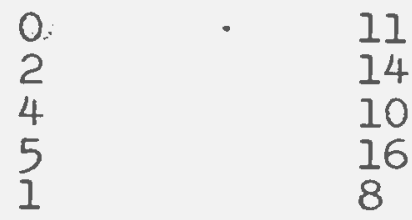

0

0

5

2

0

2

0

2

1

0

0

3

1

1

0

1

4
1
Repro.

12

11

8

13

12

16

16

17
15

4
5
8
10
9

5
7
14
10
10

9

15

11

10

12

2
8
5
8
9

13

18

10

9 
Subjects*

Disc.

Copying

Repro.

21151

21152

21153

21154

21155

2
7
1
4
2

0
1
1
2
0

8

21251

21252

21253

21254

21255

21161

21162

21163

21164

21165

2
8

1

0

9
1

6

7

7

4

2
3

9

8

8
5

$\begin{array}{ll}1 & 0 \\ 1 & 1 \\ 5 & 0 \\ 4 & 1 \\ 2 & 0\end{array}$

5
8

8

8

9

21261

1

0

11

21262

21263

21264

21265

31

8

2

12

5
3

7
7

21171

0

6
7
5
5
6

21271

21272

21273

21274

21275

3
$?$
5
1
2

5

0

0

1.

2
3

$\frac{1}{2}$

0

0

0

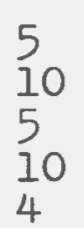

21181

21182

21183

21184

21185

3
3
1
3
1

0

0

1

0

7
4
4
10
7

21281

0

0

8

21282

21283

$\frac{1}{3}$

0

10

1

21285

0

0

9
6
9 
Subjects*

22111
22112
22113
22114
22115

22211

22212

22213

22214

22215

22121

22122

22123

22124

22125

22221

22222

22223

22224

22225

22131

22132

22133

22134

22135

22231

22232

22233

22234

22235

22141

22142

22143

22144

22145

22241

22242

22243

22244

22245
Disc .

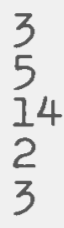

8

8

9

14

0

3

4

7
3

7

2

6

6

2
4

3

1

1
2
5
8
3

6

2

3

0

0

5
3
2
3
5
Copying

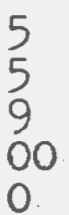

4

4

18

?

0

0

1

2
4

5
1
3
1
2

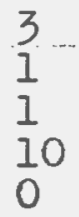

5
1
7
2
6

0

1

0

0

2

4
1
2
1
2
Repro.

14

16

16

11

13

13

15

17

15

12

10

12

10

16

14

7

15

10

13
12

13

15

12

9

15

14

13

8

7

12

10

15

12

11

8

10 
Subjects*

Disc.

Copying

Repro.-

22151

22152

22153

22154

22155

1
4
3
1
2

1

0

0

0

0

5
9
10
3
8

22251

22253

22254

22255

4

3

2
3
0
3
0

6

8

6

4

5
7
74

22161

4

6

22162

22163

22164

22165

22261

22262

22263

22264

22265

22171

22172

22173

22174

22175

22271

22272

22273

22274

22275

22181

22182

22183

22184

22185

22281

22282

22283

22284

22285

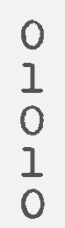

4

11

6

0

1

11

2
6
5
3
1

1

9

0

11

0

5

10

$\begin{array}{ll}5 & 6\end{array}$

0

0

0

0

3

1

1

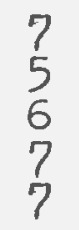

2
1
1
1
1

0
3
1
0
2

8

11

6

5
8

1
3
3
4
1

0

0

0.

1

5

4

6

1

0

6

2
3
1
0
2

1
0
0
1
0

9
10
5
10
9

*The first digit designates the sex of the child (boy or girl); the 2nd the sex of the examiner (male or female); the $3 r d$ the IQ category (high or average); the 4th the age group (one - eight); \& $5 \mathrm{th}$, the within group subject number. 
REFERENCES 


\section{References}

Ali, F., \& Costello, J. Modification of the Peabody Picture Vocabulary Test. Developmental Psychology, 1971, $5,86-91$.

Aliotti, N. Note on Validity and Reliability of the

Bannatyne Visuo-Spatial Memory Test. Perceptual and Motor Skills, 1974, 38, 964-966.

Bannatyne, A. A Comparison of Visuo-Spatial and Visual

Memory for Designs and their Relationship to other Sensori-Motor and Esycholinguistic Variables. Journol of Learning Disabilities, 1969, 9, 451-466. Belmont, J., \& Butterfield, E. The Relations of ShortTerm Memory to Development and Intelligence. In I. Lipsitt \& H. Reese (Eds.) Advances in Child Development and Behavior. New York: Academic Press, 1969. Fp. 29-82.

Benton, A. The Revised Visual Retention Test. The Psychological Corporation:: New York, 1963. Birch, H. G. \& Lefford, A. Visual Differentiation, Intersensory Integration, and Voluntary Motor Control. Monographs of the Society for Research in Ghild Development, 1967, 32 (2), (Serial No. 110): Carroll, J. Short Term Visual Memory in Five - and Six Year Old Children: Some Cognitive and Academic Correlates. Paper read at American Psychological Association, New Orleans, Louisiana, 1974. Cazden, C. B. Subcultural Differences in Child Language: on Inter-Disciplinary Review. Merrill-Palmer Quarterly, 
$1966,12,185-219$.

Colarusso, R. The Development of a Motor-Free Test of

Visual Perception. Unpublished Doctoral Dissertation, Temple University, 1971.

Crandall, V. C. Reinforcement Effects of Adults Reac-

tions and Nonreactions on Children's Achievement

Expectations. Child Development, 1963, 34, 335-354.

Dunn, I. M. Peabody Picture Vocabulary Test. Minneapolis; American Guidance Service, 1959.

Eliot, J (ed.) Human Development and Cognitive Processes.

New York: Holt, Rinehart \& Winston, 1971.

Flavell, J. H., Beach, D. R., \& Chinsky, J. M. Spontaneous

Verbal Rehearsal in a Memory Task as a Function of

Age. Child Development, 1966, 37, 283-300.

Fuller, G (Chairman): Visual Memory Symposium. American

Psychological Association Convention, New Orleans, Louisiana, 1974.

Gaines, R. The Discriminability of Form among Young

Ghildren. Journal of Experimental Psychology, 1969,

8 (3), 418-431.

Graham, F. K. \& Kendall, B. S. Memory-for-Designs Test.

Psychological Test Specialists, 1960.

Haith, M. M. Development Changes in Visual Information

Processing and Short-Term Visual Memory. Human

Development, 1971, 14 (4), 249-261.

Hanawalt, N. G. Review of Revised Visual Retention Test. In Buros, O. K. The Fifth Mental Measurements Yearbook. Highland Park, N.J.:: Gryphon Press, 1959. 
Hess, R. D. \& Bear, R. M. Early Education: Current Theory, Research and Action. Chicago: Aldine, 1968. Husted, J., Wallin, K., \& Wooden, H. The Psychological Evaluation of Profoundly Retarded Children with the Use of Concrete Reinforcers. Journal of Psychology, 1971, 77, 173-179.

Issac, B. Perceptual-Motor Development of First-Graders as Related to Class, Race, and Factors of Motivation, Personality, and Visual Discrimination. Unpublished Doctoral Dissertation, Rutgers University, 1971. Kagan, J., \& Kogan, N. Individual Variation in Cognitive Processes. In Mussen, P. (Ed.) Carmichoel's Manual of Child Psychology. New York: Wiley, 1970. Pp. 12731365 .

Keely, K. Age and Task Effects in Short-Term Memory of Children. Perception \& Psychophysics, 1971, 9, $480-482$.

Kirk, S. A., McCarthy, J. J. \& Kirk, W. Illinois Test of Psycholinguistic Abilities. Urbana: University of Illinois Press, 1968.

Kulberg, J. The Effect of Social Class, Age, and Sex upon the Reward Value of Certain Positive Reinforcers. Unpublished Doctoral Dissertation, George Peabody College, 1967.

Maccoby, E. E., \& Hagen, J. W. Effects of Distraction upon Central Versus Incidental Recall: Developmental Trends. Journol of Experimental Child Psychology, 1965,2 , 280-289.. 
Newcommer, P., \& Hammill, D; Visual Perception of Motor Impəired Children: Implications for Assessment. Exceptional Children, 1973, 1, 335-336.

Nickel, H. Capability to Differentiate Visually and General

Intelligence Level by Preschool Children. Psychologische Rundschau, 1969,20 (4), 257-274.

Poskewicz, C., \& Weaver, S. J. The Effects of Motivation on Differential Diagnosis in Visual Memory Ability in Elementary School Children. Unpublished, 1975. Payne, R. W. Review of Memory for Designs Test. In Buros, O. K. (ed.) The Fifth Mental Mersurements Yearbook. Highland Park, N.J.: Gryphon Press, 1959. Ramey, C., \& Goulet, L. R. Effects of Spatial Separation of Stimulus, Response, and Reward in Discrimination Learning by Children. Child Development, 1971, 3, 978-982.

Reese, H. W. Verbal Mediation as a Function of Age Level. Psychological Bulletin, 1962, 59, 502-509.

Reese, H. W. \& Lipsitt, L. P. Experimental Child Psychology. New York: Academic Press, 1970. Rosenblith, J. Judgments of Simple Geometric Figures by Children. Perceptual and Motor Skills, 1965, 2l, 947-990.

Rowley, V. \& Stone, F. B. Changes in Ghildren's Verbal Behavior as a Function of Social Approval, Experimenter Differences and Child Personality. Child Development, 1964, 35, 669-676.

Silverstein, A. B. Perceptual, Motor, and Memory Functions 
in the Visual Retention Test. American Journal of Mental Deficiency, 1962, 66, 613-627.

Qualitative Analysis of Performance on the Visual Retention Test. American Journal of Mental Deficiency, 1966, 66, 109-113.

Simpson, S. A. Intelligence and Perception in C. B. Children. Israel Annals of Psychiatry and Related Disciplines, $1974,1,68-84$.

Stodolsky, S. \& Karlson, A. Differential Outcomes of a Montessori Curriculum. Elementary School Journal, $1972,8,419-433$.

Wedell, K., \& Horne, I. E. Some Aspects of PerceptuoMotor Disability in 5\% Year Old Children. British Journal of Educational Psychology, 1969, 2, 174-182. Zach, L. \& Kaufman, J. How Adequate is the Concept of Perceptual Deficit for Education. Journal of Learning Disabilities, 1972, 6, reprint. 